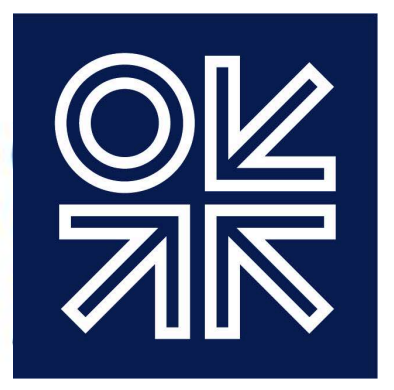

THE OXFORD

INSTITUTE

FOR ENERGY

STUDIES

May 2018

\title{
Decarbonisation of heat and the role of 'green gas' in the United Kingdom
}

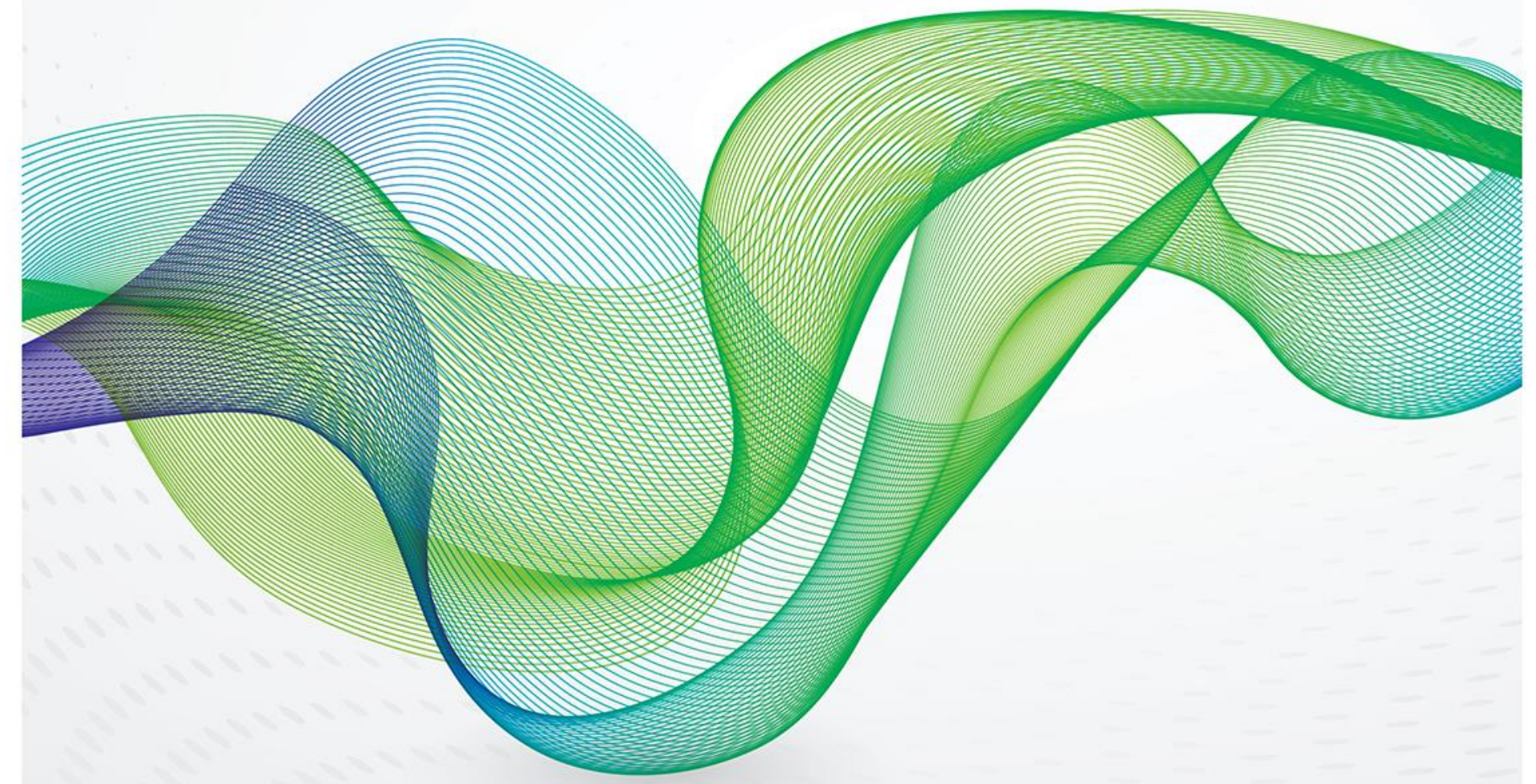


The contents of this paper are the author's sole responsibility. They do not necessarily represent the views of the Oxford Institute for Energy Studies or any of its members.

Copyright $\odot 2018$

Oxford Institute for Energy Studies

(Registered Charity, No. 286084)

This publication may be reproduced in part for educational or non-profit purposes without special permission from the copyright holder, provided acknowledgment of the source is made. No use of this publication may be made for resale or for any other commercial purpose whatsoever without prior permission in writing from the Oxford Institute for Energy Studies.

ISBN 978-1-78467-107-5

DOI: https://doi.org/10.26889/9781784671075 

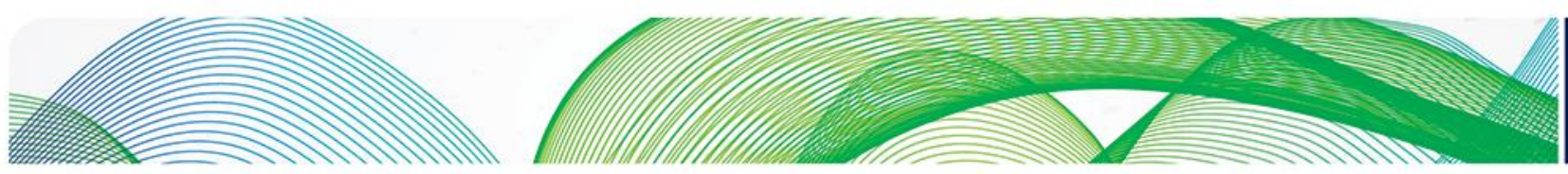

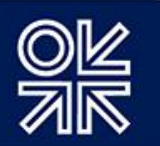

\section{Contents}

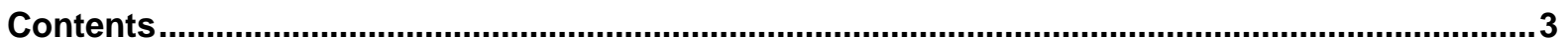

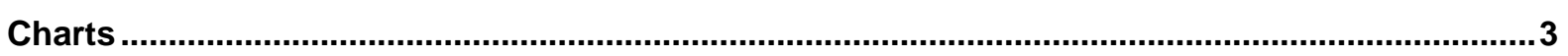

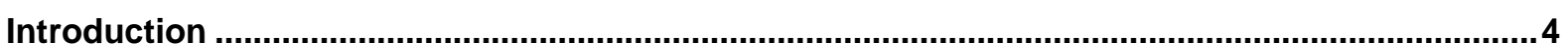

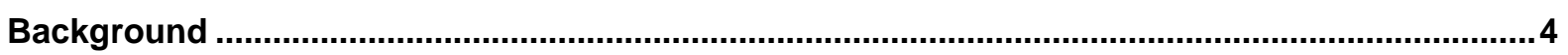

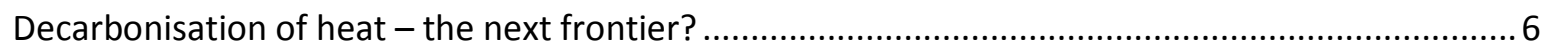

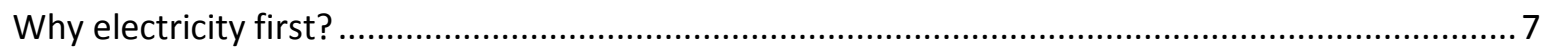

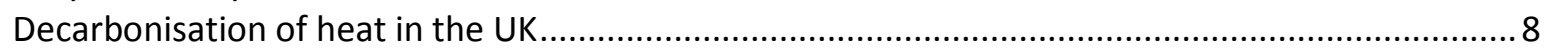

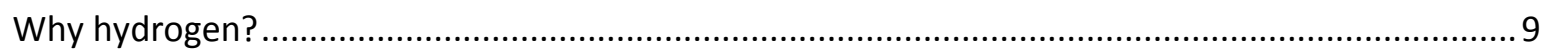

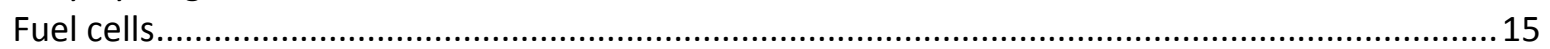

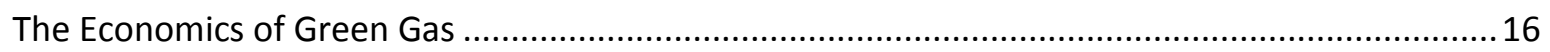

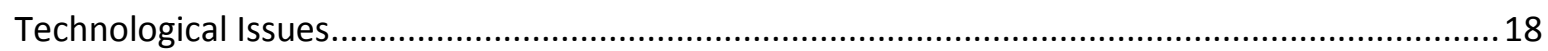

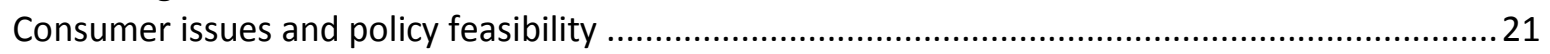

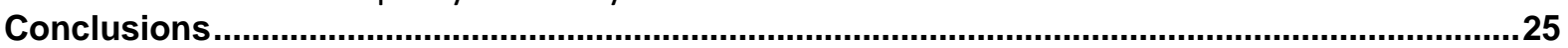

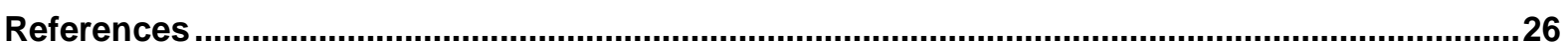

\section{Charts}

Chart 1: EU-28 gross inland consumption by fuel -2015 (\% total) ......................................... 5

Chart 2: Gross electricity generation by fuel - EU-28 - 1990-2015 (TWh) ................................. 6

Chart 3: Greenhouse gas emissions by National Communication sector, 1990-2015 .........................9

Chart 4: Comparison of heat and electricity variability across a year (domestic and commercial) -

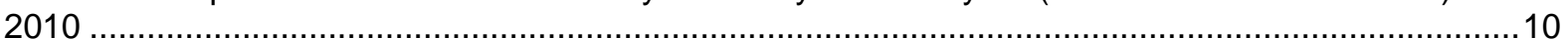

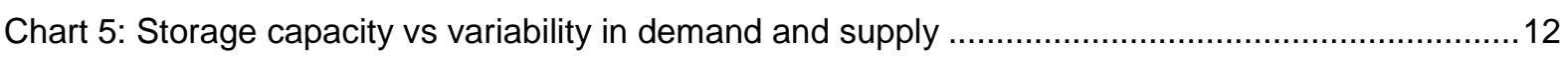

Chart 6: Scenario for a hydrogen energy economy ............................................................... 16

Chart 7: Annual additional costs $(£)$ versus consumption (MWh) ............................................... 17 

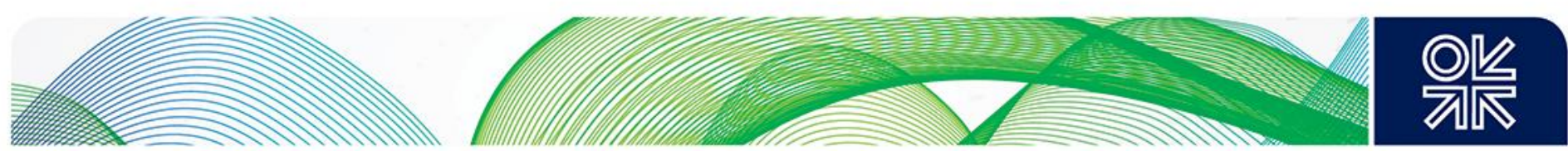

\section{Introduction}

This paper looks at the challenge of decarbonising the heat sector and the possible role of 'green gas' in meeting this challenge. It focuses in particular on the United Kingdom, where 'green gas' is receiving the most sustained attention. It draws on a number of published studies of the economic and technical feasibility of 'green gas' but does not seek to extend this particular area of analysis; rather it concludes from the studies that a prima facie case for the option has already been made and seeks to examine the steps which might be needed, and the policies which might be required, to convert it from a theoretically promising idea to a practical reality. The paper concludes that the socio-economic and policy questions are likely to prove an even greater challenge than the economic and technical issues which have received the most attention hitherto.

The paper is designed to complement a parallel paper, prepared by Anouk Honore of the OIES Gas Programme, which looks at the Decarbonisation of heat in Europe: impacts for natural gas demand and provides a more general survey of the options and challenges in Europe more widely.

\section{Background}

The 'green gas' debate is relatively recent. Decarbonisation policies up to now have mainly affected electricity, leading to fundamental changes and challenges for the sector, as documented in a number of OIES studies ${ }^{1}$. Nearly all aspects of the power sector have been affected - finances, operations, markets, business models - and government intervention has increased. Most of these consequences were unanticipated and in many cases unintended. If Europe is to meet its goal of reducing emissions by at least $80 \%$ by 2050 as compared with 1990 , it will soon face a new set of challenges - the decarbonisation of the heat and transport sectors. The impact on these sectors could be even more profound and it is important that the implications are considered carefully.

Natural gas has been relatively sheltered from the decarbonisation process so far but, as the focus starts to turn to heat, this could change. Natural gas is the biggest single source of heat in Europe; conversely, heating is gas's largest single market, so its future is closely intertwined with what happens in the heat sector. The possible range of outcomes is huge. On the one hand, gas could virtually disappear from this market; on the other hand, it is possible that demand for gas in heat could actually increase if the 'green gas' option develops effectively.

In its Future Energy Scenarios (NG 2017) the National Grid produces a fairly conservative set of forecasts which nonetheless illustrate the likely difference in the impact on gas and electricity. For electricity the starting point is 2016 electricity demand of 306TWh. Depending on the scenario, this could range from 321TWh to 383TWh by 2050. In other words, an overall increase in consumption is likely in any scenario. Moreover, because of the growth in intermittent renewable plants the increase in capacity requirements is likely to be even greater. With natural gas on the other hand, the scenarios suggest that the question is by how much gas demand could fall. Annual gas demand was 817TWh in 2016; it could range from 398TWh to 772 TWh by 2050 , depending on the scenario.

Decarbonising the heat sector is a more urgent priority in the UK than many other countries, for the reasons discussed below, and the use of hydrogen as a replacement for natural gas in the heating sector has emerged as a serious option; indeed, to a large extent the current debate in the UK focuses on the choice between the use of gas and electricity networks. The main 'green gas' option in the UK involves the use of hydrogen produced from methane, via steam reforming combined with carbon capture and storage (CCS), creating a low carbon heating source. The option has been shown to be technically (and probably economically) feasible, at least as compared with other low carbon options. 

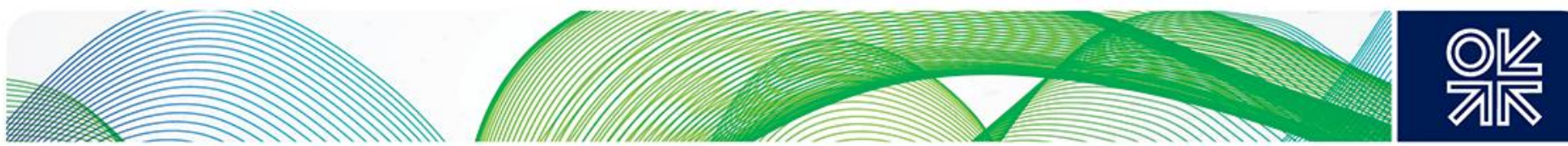

It is receiving particular attention in the UK because of its special circumstances, as discussed in more detail below.

In more general terms, however, the UK is facing essentially the same issues as other countries, and other European countries in particular. Decarbonisation policies worldwide have so far concentrated on two broad categories of measure: energy efficiency and the promotion of renewables generation (OEF 2016). Europe has been a pioneer in climate change action and the impact on its markets has been very visible in recent years. In the early 2010s, demand for all fuel sources, apart from renewables, went into decline; renewables have grown steadily, as shown in Chart 1.

\section{Chart 1: EU-28 gross inland consumption by fuel - 2015 (\% total)}

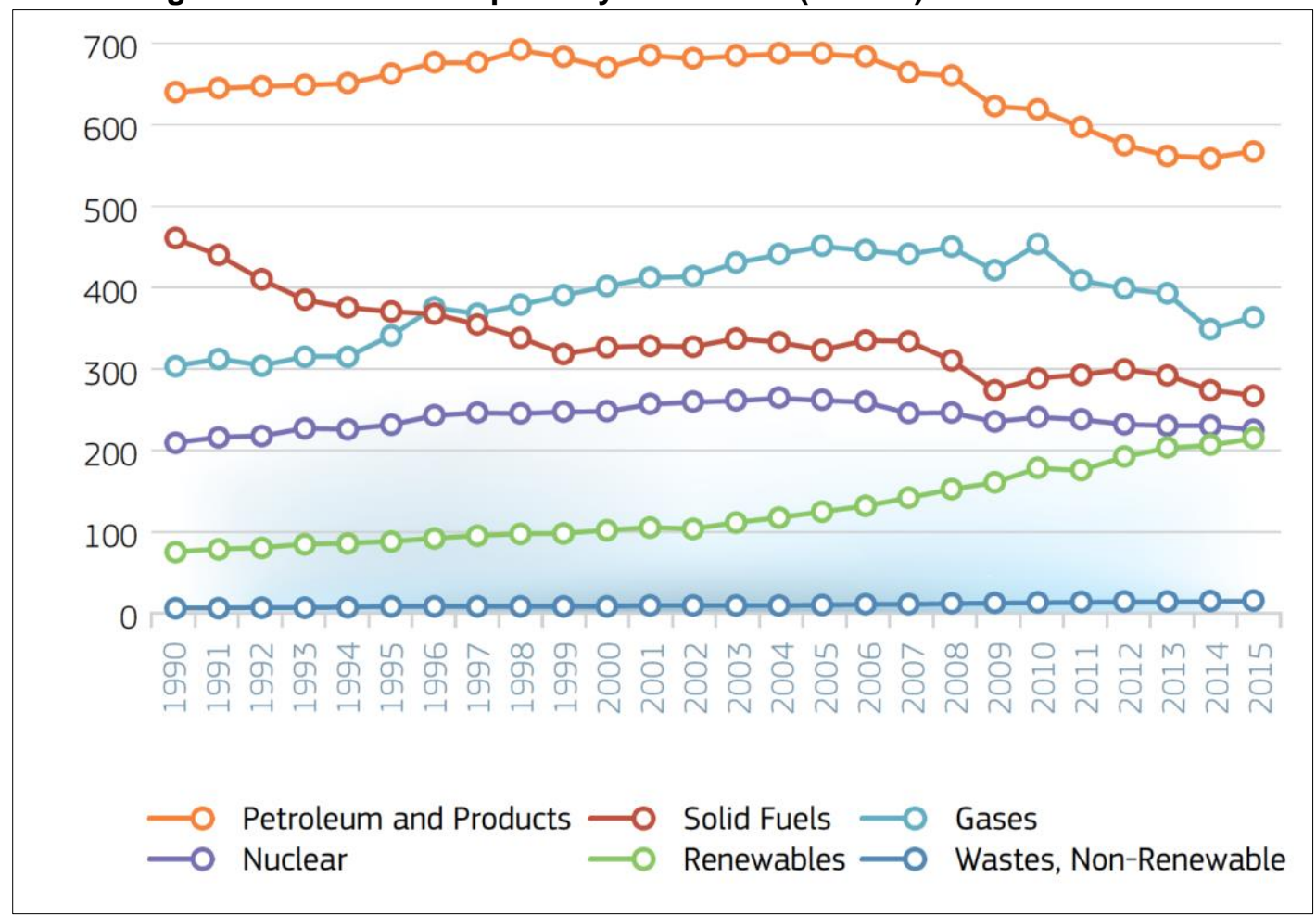

Source: EU Energy in Figures 2017

While there have been signs of a recent levelling off, or even a return to growth, demand for natural gas and other fuels remains below the level of a decade ago - the first time this has happened across Europe since the Second World War.

The growth in renewables has been driven primarily by government support schemes of various sorts and has focused on electricity, as shown in Chart 2. 

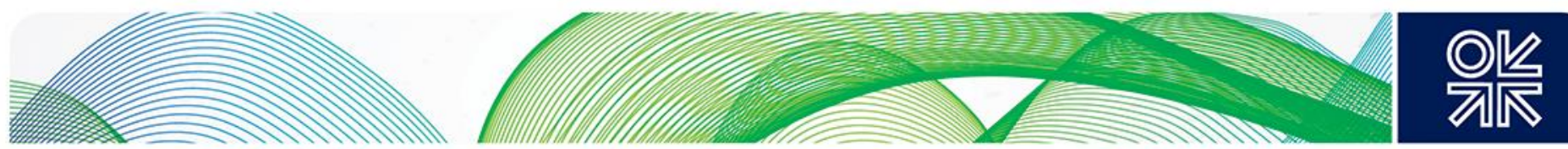

Chart 2: Gross electricity generation by fuel - EU-28 - 1990-2015 (TWh)

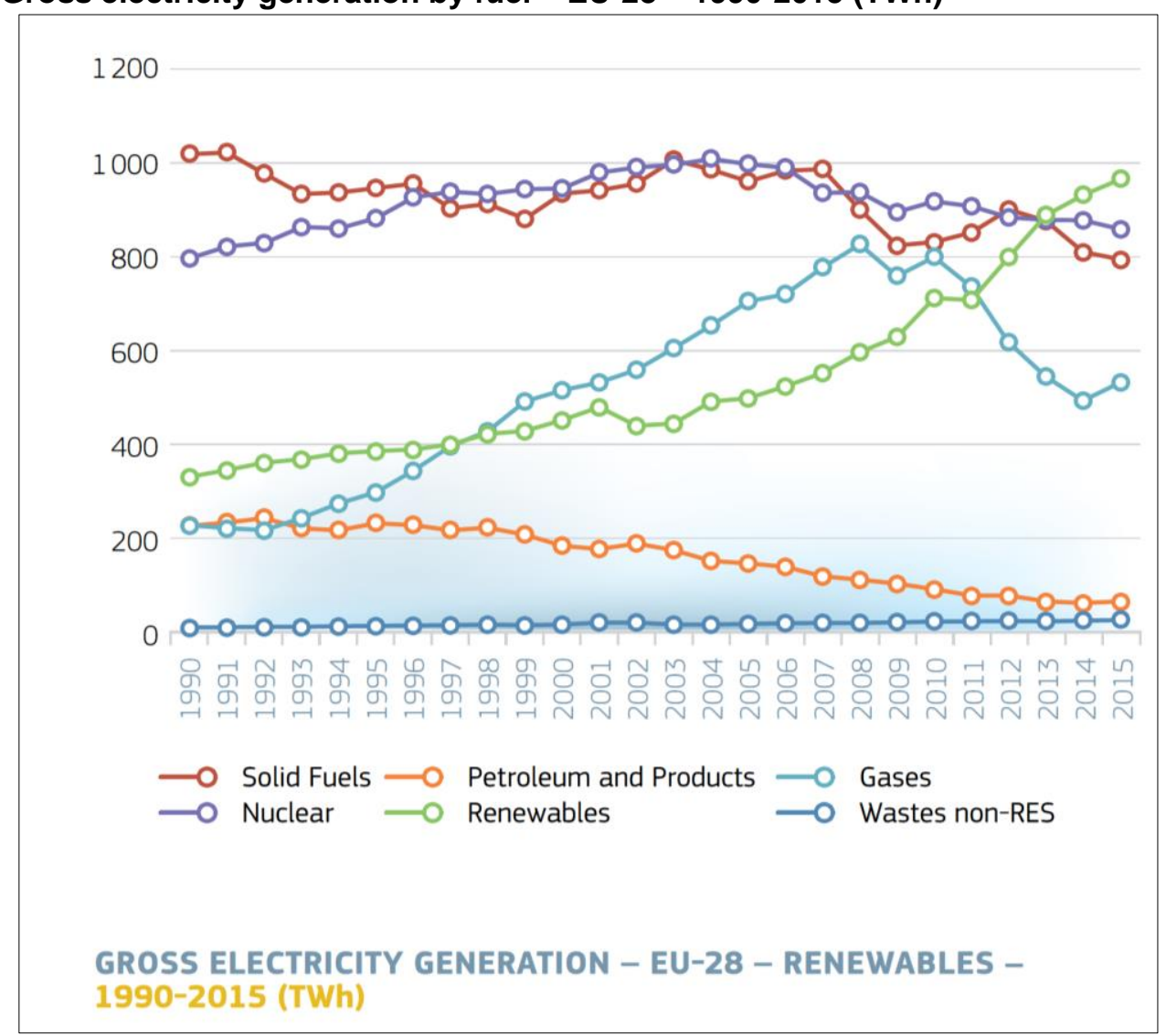

Source: EU Energy in Figures 2017

Renewables' effect on the electricity sector has been profound. There are major strains within European markets and worrying signals are appearing: falling wholesale prices at a time of rising generation costs; early plant closures; financial problems for utilities, who are nonetheless expected to engage in the biggest investment programme in history to meet carbon targets; the frequent occurrence of zero or negative prices; debates over the need for market reforms, in particular the introduction of capacity mechanisms, to underpin investment in the plants needed to maintain supply security; complaints from consumers about constantly rising prices; utilities forced into restructuring and the need to change their business models and so on. ${ }^{2}$

Most of these changes were unanticipated and unintended. The problem has been that switching to renewables has been more complicated than simply replacing one form of generation with another - it has changed the entire technical, operating and economic characteristics of the industry, effectively turning it 'upside down'. It is important to take account of the lessons from electricity when considering the next stages in decarbonisation.

\section{Decarbonisation of heat - the next frontier?}

The EU is committed to a reduction of at least $80 \%$ in emissions by 2050 . Electricity is a significant source of $\mathrm{CO}_{2}$ emissions from energy (about 35\%), but even if electricity becomes near zero carbon, other sectors will also have to contribute very significant reductions to meet this target. Heating (and 

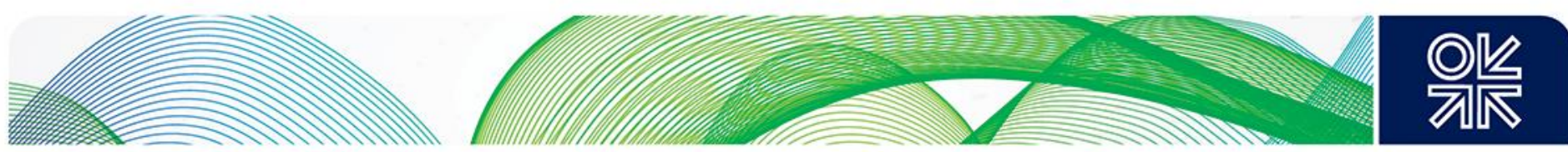

cooling) in buildings account for around $50 \%$ of energy consumption in Europe ${ }^{3}$ and $75 \%$ of this comes from fossil fuels, principally gas, which accounts for about $46 \%$ of that total. Policies for the decarbonisation of heat are therefore likely to have very significant implications for the share of gas in this market - currently the largest single market for gas in Europe.

Insofar as there is a strategy for heat decarbonisation, the default position for most analysts and policy makers has hitherto been 'electricity first' - i.e. first decarbonise electricity then electrify other sectors, like heat and transport.

\section{Why electricity first?}

The reasons for decarbonising electricity first are strong and have been widely accepted (as demonstrated in the concentration of renewables in the electricity sector to date):

- Technical feasibility Electricity can be produced from a range of energy sources; low carbon energy is quite technically feasible - indeed, a number of countries, like Norway and Iceland, already have effectively zero carbon electricity.

- Logistical simplicity Furthermore, the logistical task of introducing low carbon technology into electricity generation systems is (relatively) simple. Only a small number of installations is involved. In the UK, for instance, until recently about 30 large power stations accounted for about $30 \%$ of emissions - about the same as total transport emissions or emissions from residential buildings 4 . Furthermore, electricity networks are already fully developed - virtually $100 \%$ of the population in Europe already has access - so the implications for new infrastructure are less than for some other options.

- Political and consumer acceptability Decarbonising electricity has little direct impact on consumers' lives (except via prices) - appliances do not need to be changed and no significant behavioural adjustments have been required, at least so far. This makes it a much easier sector to deal with in terms of the politics.

- Competition and competitiveness In most of its main uses (appliances, information technology, lighting etc) electricity faces little competition. This means that any price impacts are unlikely to induce changes in consumer behaviour or economic distortions - in effect higher electricity prices are a sort of 'Ramsey tax'. The impacts on industrial competitiveness are also relatively limited, at least as compared with other sectors - relatively little electricity is traded across borders and it is a significant cost component for only a small number of specialised sectors, for which special arrangements can be developed if needed.

For all these reasons, the 'electricity first' approach has appealed to governments. For instance, in the UK the Climate Change Committee commented at an early stage in the development of UK decarbonisation strategy that 'Any path to an $80 \%$ reduction by 2050 requires that electricity generation is almost totally decarbonised by 2030' (CCC 2008, p 173) and this has been at the heart of the government's strategy to date.

Given that the first step is decarbonisation of electricity, it has seemed to many that a logical next step is to use that low carbon electricity to decarbonise other sectors. For instance, in Europe, the European Commission's Roadmap for moving to a competitive low-carbon economy in 2050 (EC 2011) sets out a plan to meet the long-term target of reducing domestic emissions by $80 \%$ to $95 \%$ by mid-century. The strategy in the roadmap is broadly similar to that adopted in the UK. The Commission notes that:

\footnotetext{
${ }^{3} \operatorname{COM}(2016) 51$

${ }^{4}$ Author's calculations - as the large Drax power station has converted to biomass, and coal use has declined to historically low levels, reported emissions from these stations have declined significantly this decade.
} 

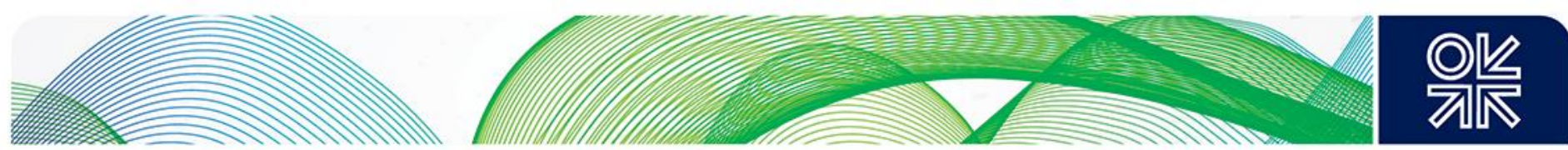

\begin{abstract}
'Electricity will play a central role in the low carbon economy. The analysis shows that it can almost totally eliminate $\mathrm{CO}_{2}$ emissions by 2050 , and offers the prospect of partially replacing fossil fuels in transport and heating... The share of low carbon technologies in the electricity mix is estimated to increase from around $45 \%$ today to around $60 \%$ in 2020 , including through meeting the renewable energy target, to 75 to $80 \%$ in 2030 , and nearly $100 \%$ in 2050 .' (EC 2011, p6)
\end{abstract}

Many analysts have also followed this approach in their modelling - for instance, the Intergovernmental Panel on Climate Change in its Fifth Assessment Report ${ }^{5}$ commented that:

'Many mitigation scenario studies....have three generic components: (1) decarbonise power generation; (2) substitute electricity for direct use of fossil fuels in buildings and industry (see Sections 9.3 and 10.4), and in part for transportation fuels (Chapter 8); and (3) reduce aggregate energy demands through technology and other substitutions.'

Most recently the Energy Transitions Commission (ETC 2017) set out this approach as the first critical step in a global strategy:

'Energy transition 1 - decarbonisation of power combined with extended electrification could account for the largest share of emissions reductions between now and 2040.'

So this approach is more or less the conventional wisdom. But recently it has come under more intense scrutiny, especially in the UK (as explained below). That scrutiny has revealed problems which put the approach into question, with the result that 'greening gas' is now emerging as a possible alternative.

\title{
Decarbonisation of heat in the UK
}

The main reason why the UK is considering strategies for the decarbonisation of heat is that it has a particularly rigorous framework for achieving decarbonisation, underpinned by the Climate Change Act 2008 (CCA). This sets a binding target for the UK for the year 2050 (of an 80\% reduction in greenhouse emissions as compared with 1990 levels) and provides for the establishment of a trajectory to that goal based on five-year 'carbon budgets' (i.e. a level of emissions to be achieved over each succeeding fiveyear period). The budgets are set with advice from the Committee on Climate Change (CCC), also set up under the Act, which advises the government and reports to Parliament on progress in reducing emissions. Once the budgets have been agreed, they are also binding (i.e. the Secretary of State has a duty, first to set the budgets - for periods at least 12 years ahead - then to ensure that emissions do not exceed that budget).

The framework has proved very successful - the UK has already achieved reductions in emissions of over $40 \%$. However, the future challenges are significant. The UK budget for the period 2028-2032 involves a $57 \%$ reduction in emissions. To achieve that it will need to start making significant reductions in the residential heat sector (and transport), which have contributed little so far - see Chart 3 . The CCC has made it clear that emissions from the sector will need to be near zero in 2050 (CCC 2016). 

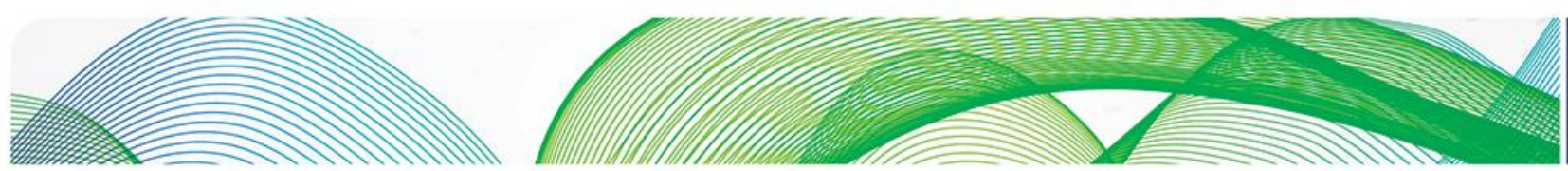
O는

Chart 3: Greenhouse gas emissions by National Communication sector, 1990-2015

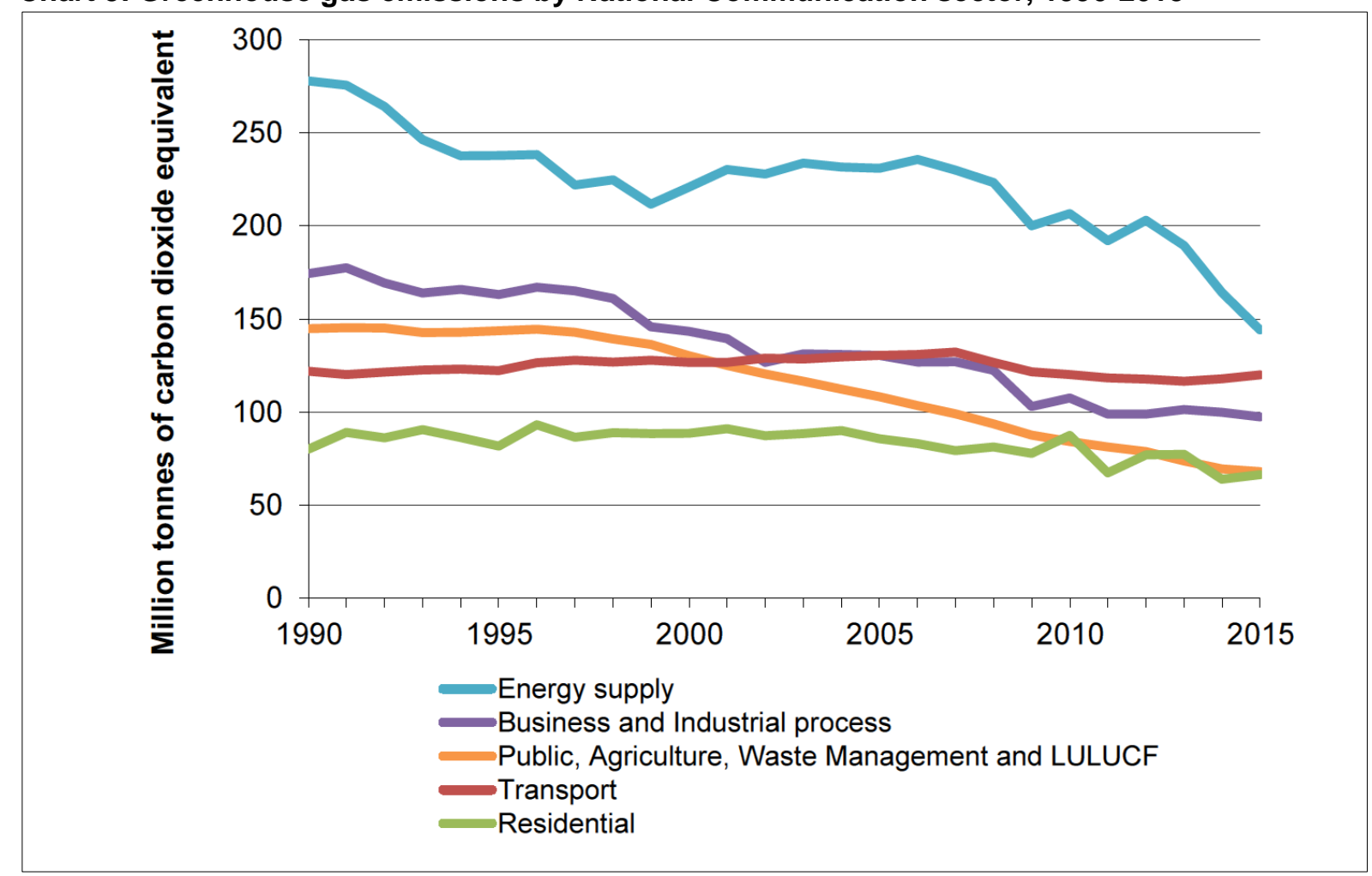

Source: UK Energy in Brief 2017

\section{Why hydrogen?}

To understand why 'green gas' in the form of hydrogen is central to the UK debate, it is important to recognise some significant features of the UK energy landscape. In effect, it is composed of three separate sectors, each with their own fuel of choice:

- Electricity: production is changing in the ways discussed above. On the demand side electricity is mainly used (over $75 \%$ ) in applications where there is little competition, such as appliances, information and communications technology, lighting, and static motors such as pumps.

- Heating: dominated by gas (which provides about $80 \%$ of heating).

- Transport: monopolised by oil (over $90 \%$ ).

This tripartite division is not just a matter of chance. The fuels each have qualities which make them well suited to the sector concerned. For people to change their energy source is not just a matter of changing from one energy supplier to another. It may mean a change in the range of capabilities being supplied and therefore in their whole relationship with the service in question. On a larger scale, we have the same problem as was encountered with changing fuel sources in electricity generation - it is not just a matter of substituting one source for another; the whole sector may need to change and changes will be needed at consumer level as well as upstream.

One reason for (and consequence of) the dominance of gas in the UK's heating sector is that there are few alternatives to the gas and electricity networks when it comes to options for the decarbonisation of 

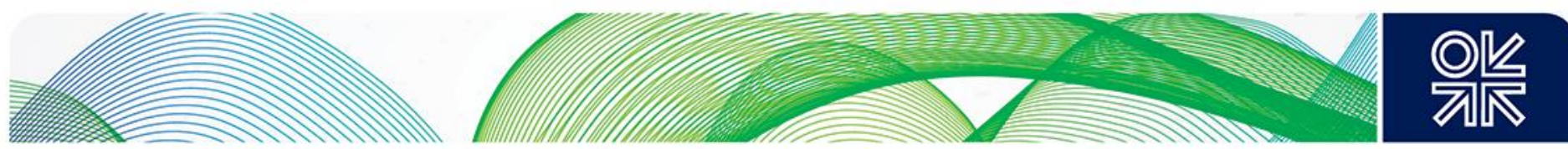

heat. There is very little district heating in the UK - it supplies less than $2 \%$ of UK heating demand ${ }^{6}$. While there is some scope for expansion, especially in new developments (and the government is trying to encourage this), retrofitting large areas is likely to be both prohibitively expensive and timeconsuming, especially given the UK's relatively extensive housing patterns - the preference for individual houses over apartments. Similarly, with biomass heating, there is some scope for expansion, but most commentators agree that it is limited. Biomass makes up only $3 \%$ of UK energy supply and there are major question marks over its sustainability and environmental impacts. ${ }^{7}$

Energy efficiency will of course be a very important part of the overall strategy, whatever route is followed; in particular it can help reduce investment costs. But energy efficiency on its own (i.e. without fuel switching) cannot meet the emissions reduction targets. That would require replacing the entire UK building stock within a few decades. Even small-scale developments of low carbon housing have proved very difficult and the investment requirements for full-scale retrofitting of the UK's old and inefficient housing stock on to a zero carbon basis would be prohibitive.

So the UK must consider how the gas and electricity networks can be used to contribute to decarbonisation. As noted above, the earlier assumption was that electricity was the obvious option, but this has come into question. The problems can be summarised in Chart 4.

\section{Chart 4: Comparison of heat and electricity variability across a year (domestic and commercial) -2010}

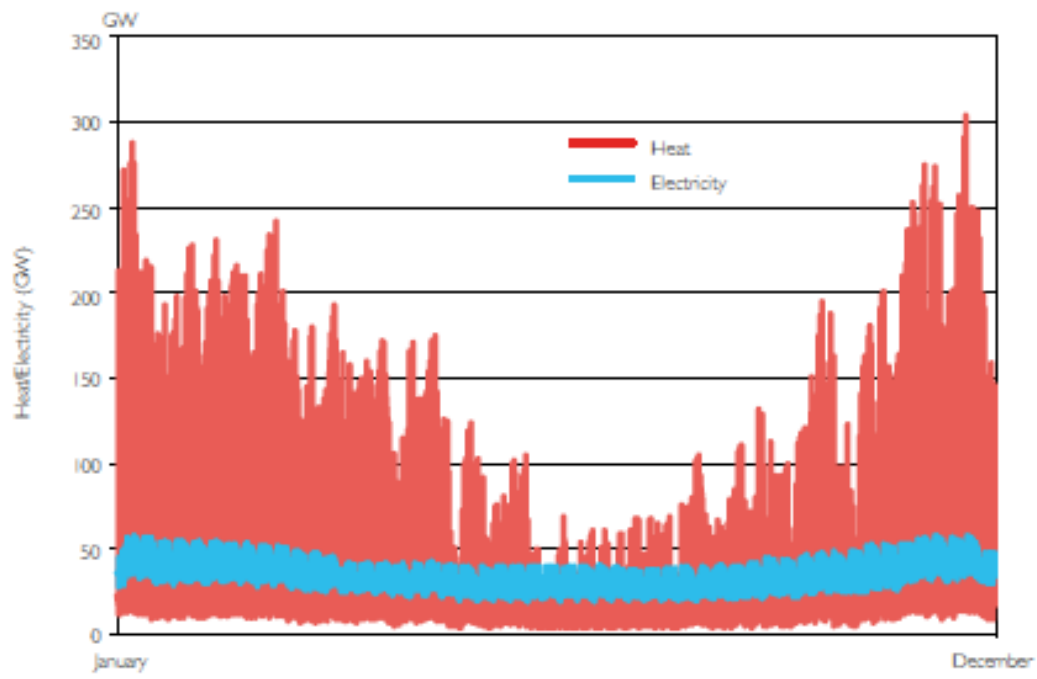

Source: DECC 2013

As the Chart shows, peak heat demand is very much higher than peak electricity demand (about 6 times as high) and heat demand is much more variable across the year. Meeting heat demand directly by electricity would impose enormous strains on the grid unless further changes were made to the system.

Of course, the chart may overstate the problem - as far as peak demand is concerned, the difficulties could be mitigated by a combination of better insulation and the use of heat pumps. Heat pumps are one potentially attractive option for decarbonising heat, given their high levels of efficiency (see Box). With better levels of insulation further reducing the energy required, the extra demand needing to be 

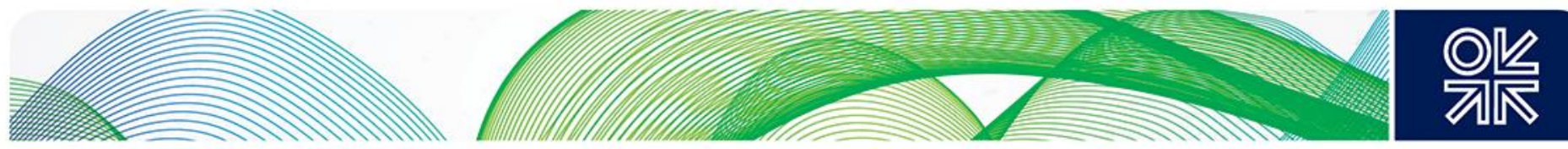

met might be reduced to perhaps twice current electricity peak levels ${ }^{8}$. But even then it would be a major challenge. Furthermore, there are major upfront capital costs for consumers in the pumps themselves and the extra insulation required; in addition, it is likely that there would be significant changes in the consumer experience. Heat pumps tend to deliver energy slowly and steadily and may not be able to adjust their output in response to a sudden cooling of the external temperature (when their own efficiency tends to be at the lowest in any event). Consumers may therefore resort to other means of boosting peak heat delivery, adding to the cost, practical difficulties and potentially emissions.

\section{Heat Pumps}

Heat pumps are essentially devices which transfer heat from one place to another; they move it in the opposite direction from that normally dictated by the laws of thermodynamics, that is they effectively take heat from a cold space and transfer it to a warmer one.

They are designed to move heat, rather than to generate it as such (though some heat is generated as a by-product of the process) and therefore normal definitions of efficiency are not strictly relevant. However, they can achieve high 'coefficients of performance' - the amount of heat transferred can be three or four times greater than the amount of power consumed by the pumps, so they can lead to a significant reduction in energy consumption. On the other hand, they involve high upfront costs, typically costing about 20 times as much as a conventional resistance heater.

Heat pumps are in fact familiar today in the form of air conditioners and refrigerators, but they can be used for heating as well as cooling - indeed it is possible to buy reversible heat pumps which can serve both purposes, by the use of a reversing valve. For countries which have both high heating requirements (in winter) and cooling requirements (in summer) they can therefore be particularly attractive. However, this flexibility is less relevant in the UK where there is very little residential air conditioning demand.

There are two main versions of the technology:

Air source heat pumps operate like traditional air conditioners in reverse; they extract heat from the outside air and transfer it into the building. A typical system would cost around $£ 6,000$ to $£ 8,000$ to install. However, the UK Energy Savings Trust ${ }^{9}$, while encouraging consumers to consider this option, warns that 'unlike gas and oil boilers, heat pumps deliver heat at lower temperatures over much longer periods. During the winter they may need to be on constantly to heat your home efficiently. You will also notice that radiators won't feel as hot to the touch as they might do when you are using a gas or oil boiler.' Air source heat pumps also get less effective as the outside air temperature cools, which can exacerbate the problem and may lead consumers to desire additional peak heating.

Ground source heat pumps use underground pipes filled with a mixture of water and antifreeze to transfer heat from the earth into a building. They have the advantage that the temperature underground is much more constant throughout the year than air temperatures so they are generally more efficient than air source pumps; on the other hand, they are more expensive and complicated to install.

In practice, therefore, attempts to encourage the use of heat pumps in the UK have hitherto proved largely unsuccessful, because of a combination of the change in the consumer experience, the high initial $\operatorname{cost}^{10}$, and the lack of clear consumer benefit. While it might be possible to provide stronger incentives to increase the attractiveness of heat pumps for consumers without regulatory underpinning, this would likely only encourage take-up of the technology for those with existing electric heating. Given

\footnotetext{
${ }^{8}$ Eyre and Baruah 2015

${ }^{9} \mathrm{http}: / /$ www.energysavingtrust.org.uk/renewable-energy/heat/air-source-heat-pumps

${ }^{10}$ Element 2012
} 

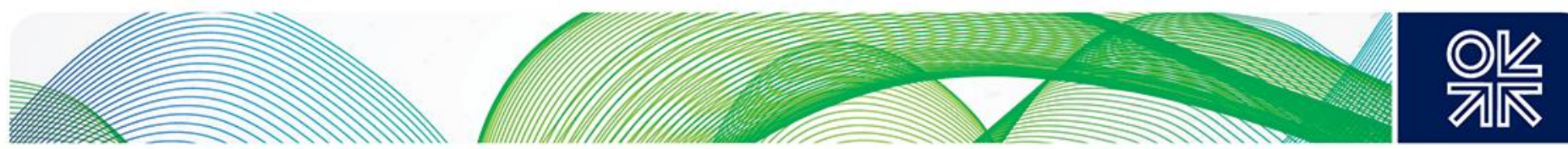

the extra cost and the loss of convenience it is very difficult to see how consumers could be persuaded to change from gas heating.

Furthermore there is a huge storage issue arising from the variability of heat demand. The electricity industry is already encountering the problem of balancing supply and demand because of the penetration of intermittent sources. For instance, there are extended periods without significant amounts of wind in the UK ( 10 days to a fortnight), even in winter when demand is peaking. The sector is facing major challenges in relation to decarbonisation - adding an enormous and highly peaky new form of demand could impose intolerable strains.

One reason why gas dominates heating in the UK is the relative ease of storage - at least as compared with electricity. While it is true that very significant strides are being taken in improving electricity storage via batteries and the like, it still remains very expensive and small scale in relative terms. The big picture is show in Chart 5 below; batteries cannot yet meet wind variability in the UK, much less the variability in seasonal heat demand.

\section{Chart 5: Storage capacity vs variability in demand and supply}

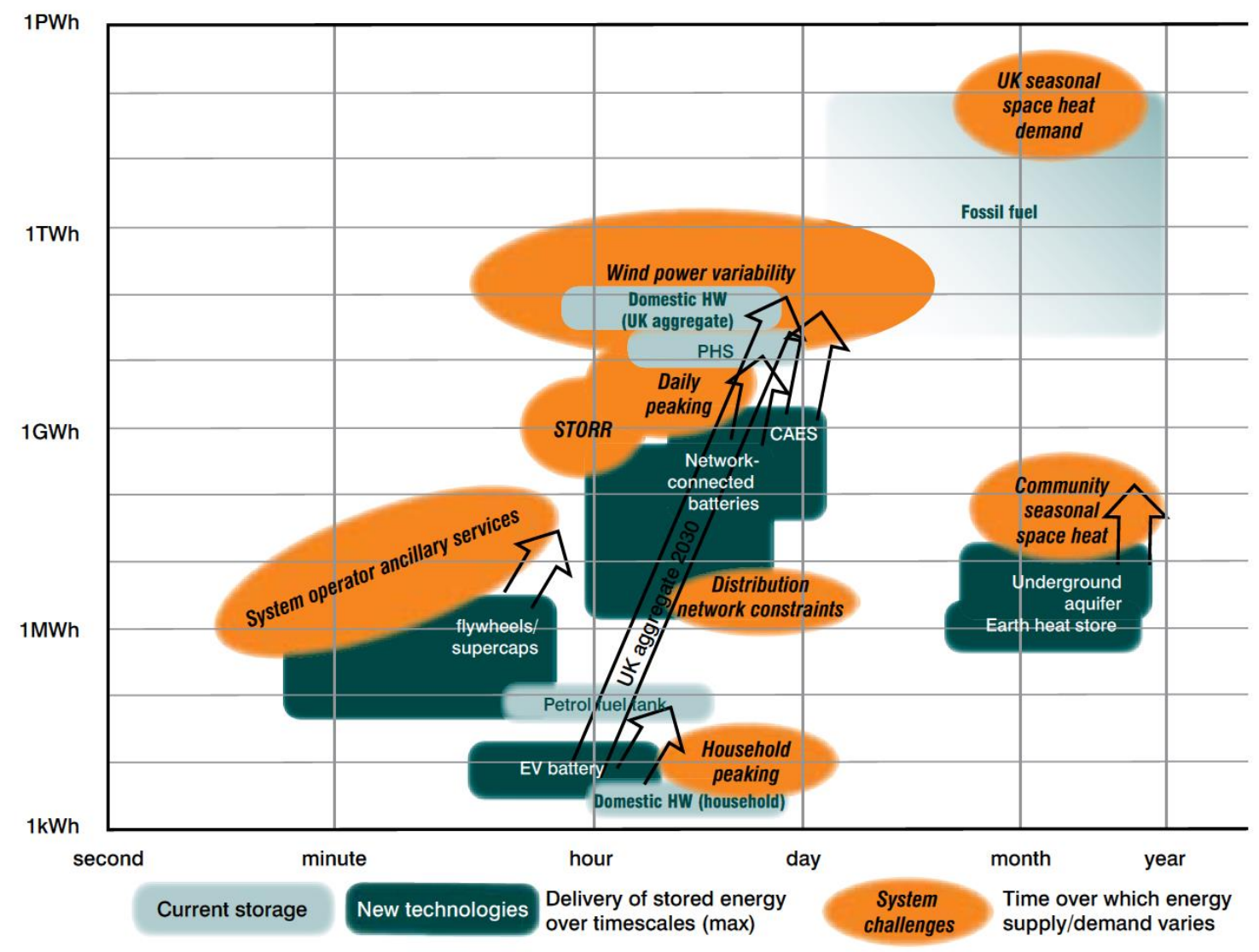

Source: ERP 2011

While it is true that future cost reductions (as shown by the arrows in the chart) could improve the relative cost-effectiveness of electricity storage, it is very unlikely that it can happen sufficiently quickly to overcome the huge gap. By way of comparison, battery storage generally costs over $\$ 200 / \mathrm{kWh}$ to establish currently, and the industry is aiming for its 'Holy Grail' of $\$ 100 / \mathrm{kWh}$. Meanwhile, gas storage in, say salt caverns costs about 30 cents/kWh to develop (ERP 2011) and short term gas storage via 'linepack' is even cheaper. In terms of scale, the UK's capacity for electricity storage (mainly in pumped 

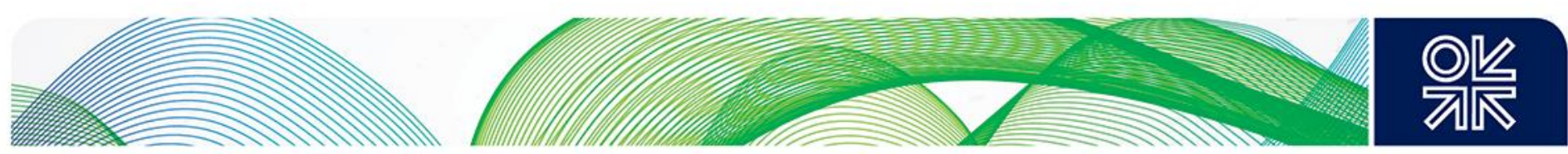

storage) is less than $30 \mathrm{GWh}$ - perhaps an hour's worth of demand; gas storage is nearly $50 \mathrm{TWh}$ over 1,500 times as much (ERP 2011).

As the problems with the electricity option become more apparent, options to decarbonise through the use of the gas network start to look more attractive. Although in principle this could involve a number of options - including biogas, synthetic natural gas or hydrogen from electrolysis - in practice, the use of steam reforming to convert methane to hydrogen, allowing the $\mathrm{CO}_{2}$ generated to be sequestered using CCS technology, has emerged as the front-runner. Various recent studies ${ }^{11}$ have examined the option and a number of official bodies have stressed the need to make an early decision on its viability. For instance, the Climate Change Committee has said that 'the Government must set out the role of hydrogen for buildings on the gas grid in the next Parliament' (CCC 2016 - though presumably, this was not in anticipation of the UK's General election of 2017). Similarly, a recent attempt to re-energise the CCS debate in the UK calls for, among other things, a 'Heat Transformation Group' to assess the relative costs and technical feasibility of decarbonising heat via electrification or hydrogen (Oxburgh 2016, para 318). In the same vein, the National Grid called for the government to provide clarity on a preferred pathway to the decarbonisation of heat 'as soon as possible' in its 'Future of Gas' report published in March 2018. A report by the UK Energy Research Council (UKERC 2018) analyses the risks and opportunities which the move to sustainable heating, including the possible hydrogen pathway, will create for particular business sectors. Reducing the uncertainties would help address some of these risks.

The hydrogen pathway has even entered the political arena - it formed the subject of a policy paper by a Labour Party group (Green Gas 2016) and was mentioned in the Labour Party Manifesto for the 2017 General Election, which promised to 'transform our energy systems, investing in new, state-of-the-art low-carbon gas and renewable electricity production' (Manifesto 2017 p 12). The Scottish Government has called for an exploration of hydrogen, which it sees Scotland as well placed to develop (SES 2017).

In practice, the Government has not responded definitively to this challenge. In its Clean Growth Strategy (HMG 2017) the only concrete commitment was to 'phase out the installation of high carbon fossil fuel heating in new and existing homes currently off the gas grid during the 2020s, starting with new homes'. Heat seems a low priority in spending too. Only £184 million was promised for this area of technology innovation (including energy efficiency) over the period 2015-2021, compared with some $£ 841$ million for vehicle and battery technology. In terms of pathways for long-term emissions reductions, hydrogen is mentioned (HMG 2017, 56) but the Government stresses the uncertainties and that it is still developing its understanding of the best approach. In other words, not only is the Government unsure about the way forward, it is not investing any significant sums to find out.

It is not the purpose of this paper to examine the economic and technical aspects of the hydrogen option in detail. As noted above, a number of recent papers have considered this option from a technical and economic perspective, and these studies are in a sense the starting point for this paper - in the view of the author, they have taken the issue far enough to show that it could be a feasible alternative.

One of the most significant of these studies is the so-called ' $\mathrm{H} 21^{\text {' }}$ project ${ }^{12}$ which undertook a detailed examination of a particular city (Leeds in the north of England) to see if it would be practical to convert it to hydrogen. The study looked at such issues as pipeline safety and capacity, broad cost estimates, availability of CCS technology, storage sites, and so on to see if the option was broadly feasible and concluded that it would be.

The UK has a number of specific advantages in this respect, including the following:

\footnotetext{
${ }^{11}$ E.g. Green Gas 2016, KPMG 2016, MacLean et al 2016, Policy Exchange 2016, H21 2016, Policy Connect 2017, NEA 2017 ${ }^{12}$ H21 2016
} 

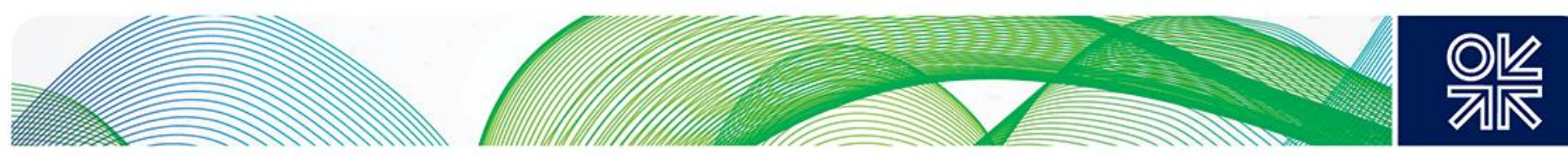

- It is in the process of converting its distribution system to polythene pipes. These pipes can carry hydrogen with little or no technical adjustment - avoiding the issue of 'embrittlement' which limits the volume of hydrogen that can be carried through traditional metal pipes.

- Distribution systems in the UK have sufficient capacity to meet demand with relatively little modification, despite the fact that hydrogen has lower calorific value than methane, partly because in many cases they developed to distribute 'town gas' (manufactured from coal) which also has a lower calorific value than natural gas. So in most cases the pipeline system itself has adequate transportation capacity and relatively little needs to be done to expand storage and other ancillary facilities.

- Although transmission lines would need to be converted to carry hydrogen, distances in the UK (which is a densely populated island) are relatively short and the costs are not prohibitive.

- As a long-standing gas producer, the UK has a number of coastal terminals where a steam reformer could be sited. These locations would be convenient both for the availability of gas for reforming and for access to depleted offshore fields for carbon storage.

The evidence from this and the other studies referenced suggests that the gas-to-hydrogen option has a number of advantages, including:

- Minimising change in the consumer experience - they could still use cooking facilities and central heating via hot water boilers as at present. The changeover to greener gas would involve disruption but of a manageable sort. There is an analogy here with the switch to North Sea gas from town gas which took place in the 1970s when areas were converted in stages. It involved constructing the necessary pipeline infrastructure, and also replacing or adapting all consumer appliances - a huge task, which caused significant, but relatively short term, disruption. Overall, the process was largely successful. The measures needed to convert areas from methane to hydrogen would be broadly similar and the precedent suggests that at least in logistical terms it should be manageable.

- Ensuring the public's acceptance of a switch to hydrogen also seems manageable. No doubt there would need to be a major campaign to persuade consumers of the safety and acceptability of hydrogen. However, town gas in the UK was a mixture of hydrogen and carbon monoxide. Using hydrogen on its own would actually raise fewer safety issues and it should be possible to adapt pipelines, burners and other equipment to meet recognised safety standards.

- The environmental advantages of a switch to hydrogen from methane are real, though would need to be examined in more detail to establish how they compared with electrification options. CCS generally manages to capture only $80-90 \%$ of emissions, so it would not remove them entirely. Nonetheless, on the face of it, this level of reduction is likely to be enough to be consistent with the long-term target.

- The economics of the approach cannot be definitively considered until full-scale demonstrations of hydrogen supply and CCS have been undertaken. Nonetheless, the studies referenced suggest that the costs of this option are at any rate not clearly worse and could be significantly lower than the electrification option once the relevant storage and other costs, and the cost of upgrading the housing stock, are taken into account (see below).

- It minimises the problem of stranded assets. Natural gas production is a naturally declining asset - it should be possible to phase it out gradually with the introduction of alternative sources. But the gas pipeline system is a huge and long-lived asset and whatever the source of hydrogen, use of this asset would reduce new infrastructure costs.

- There are potential synergies with the electricity sector. For example, it could make it possible to store electricity indirectly by converting surplus power to hydrogen via electrolysis, then using it for heat generation or even transport (via fuel cells) in a hydrogen economy - see Box. 

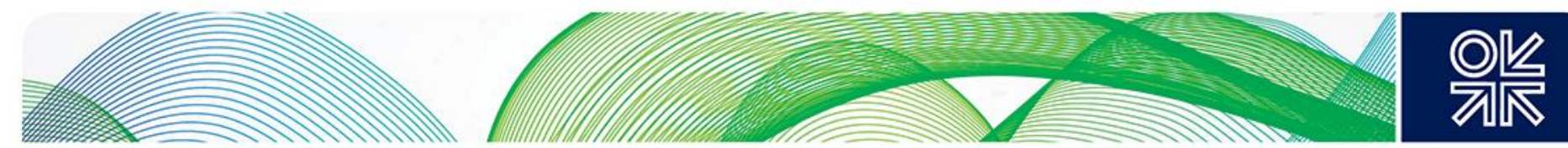

\section{The Hydrogen Energy Economy}

Many long-term scenarios for the energy sector are based around the so-called hydrogen economy. Hydrogen is of course an energy carrier rather than a primary energy source in itself, so it could be questioned whether it is needed at all - after all, electricity already exists as a universal energy carrier and if the 'electricity first' option is followed it could be the main medium for electrification. Electricity and hydrogen are effectively equivalent in creating no harmful emissions at the point of use and electricity is unlikely to be replaced by hydrogen in appliances and information technology.

There are reasons why hydrogen might nonetheless have a significant role in a low carbon economy:

Storability As noted above, this is electricity's weak spot. By comparison the cost of storing hydrogen is comparable to natural gas - that is one-thousandth or less of the cost of storing electricity.

Flexibility of generation Hydrogen can be produced from a variety of sources, including of course methane - which is the main source globally today (46\%). But of course electricity can itself be used to produce hydrogen by electrolysis of water, effectively converting electricity to storable form. While this is only a minor source of hydrogen today (around $5 \%$ of the total) its importance could increase in future with the growth of intermittent renewables. These can create swings in production leading to short-term surpluses - at present these are simply a problem for the system and intermittent generators often have to be 'constrained off' (forced to stop providing power to the system). If this power could be stored in the form of hydrogen, this could help balance the system in the short term and provide secure supply across time. Indeed a number of experiments on these lines are currently under way in island systems, using a combination of intermittent power and storage via hydrogen.

Flexibility in use Hydrogen can be combusted for heating or in internal combustion engines for transport. However, it can also be used to power fuel cells - another potential central pillar of a low carbon system (see below) - or converted into electricity via thermal generation. So it adds great flexibility to the system. Chart 6 below shows some potential interactions in the future hydrogen economy.

\section{Fuel cells}

Fuel cells use chemical energy in a fuel to create power and heat without combustion. They are capable of high efficiencies (of up to $95 \%$ ) so they offer advantages, whatever the input fuel - typically they use natural gas, LPG or other inputs at the moment. In the long run, however, to form part of an ultra-low carbon power system, they would need to be based on the use of (low carbon) hydrogen, for which they are well suited.

In many ways, fuel cells would be an attractive alternative to the direct combustion of hydrogen in a future hydrogen-based energy system, in particular because they generate power as well as heat. They would thus in principle be able to form part of an integrated all-energy system - peak electricity demand coincides with peak heat demand in the UK so in practice CHP fuel cells generate the most electricity at exactly the times when it is needed by the grid. Fuel cell CHP could therefore potentially make a significant contribution to meeting peak demand, to diversifying and decentralising electricity supply, to security of energy supply, and to decarbonisation - all at the same time (Dodds and Hawkes 2014).

Whether fuel cells live up to this potential remains to be seen, of course. They also have a number of disadvantages as compared with the alternatives - principally the high capital costs, sensitivity to operating conditions and considerable space requirements. So whereas the hydrogen boiler solution offers an evolutionary way forward, minimising the changes required from a consumer perspective, fuel cells would require much more substantial changes at every level, including that of the consumer. They are likely to make most sense in a scenario where there is an integrated vision for a low-carbon energy system based on hydrogen, as in the graphic above. 

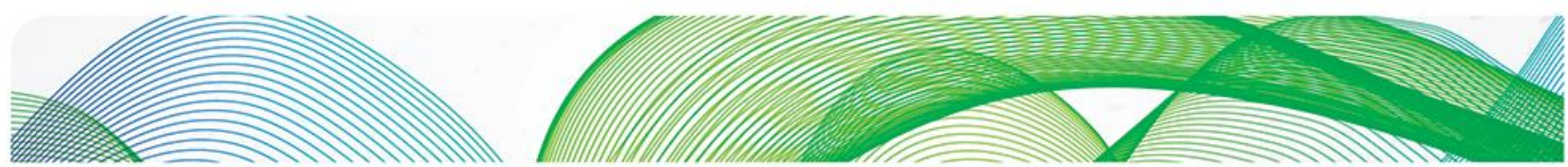
애잔

\section{Chart 6: Scenario for a hydrogen energy economy}

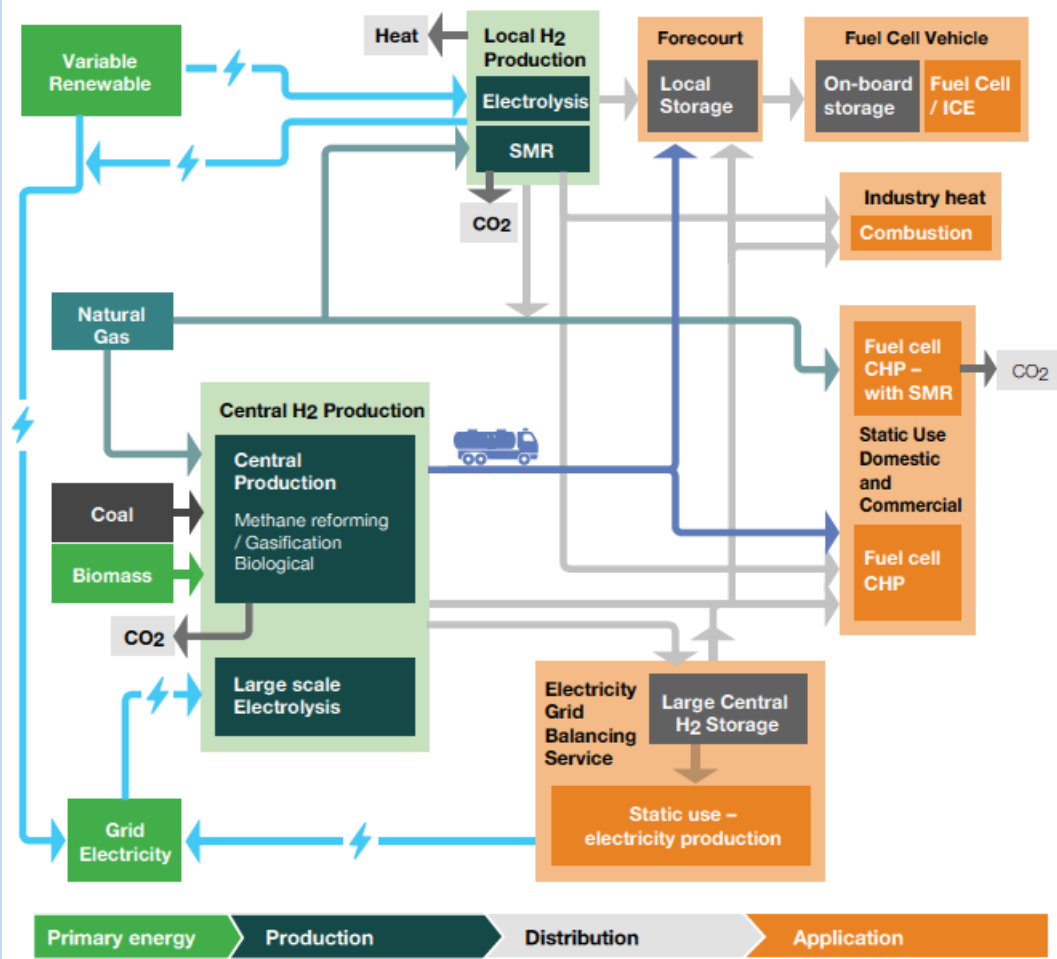

Figure 3.1: Schematic of the various hydrogen energy systems being proposed, showing the alternative production and distribution methods and uses. On the right hand side, in orange, are the various applications, where it can be used in fuel cells or burned directly in a gas turbine, domestic boiler or internal combustion engine (ICE).

Source: ERP 2016

\section{The Economics of Green Gas}

As noted above, the economic viability of this approach cannot be definitively considered at this stage. There are a number of reasons for this:

- The familiar uncertainties about major cost elements like fuel price movements, carbon taxation and overall energy demand in this sector.

- These are compounded by the major technological uncertainties - CCS itself remains to be tested at scale and the costs can only be estimated. Hydrogen supply to residential consumers is similarly novel (despite the town gas precedent) and such elements as the costs of converting consumer appliances and the regulations which will eventually prove necessary to reassure the public about supply safety remain to be determined (see below).

- Policy environment As discussed above, energy efficiency measures are likely to be part of any overall policy approach to the decarbonisation of the heat sector, and energy prices are expected to rise in almost any scenario, so both total and peak demand are unlikely to follow a business as usual trend. This factor is likely to be of particular relevance in the comparison between alternative options - for instance, electric heat pumps offer high efficiencies but would only make sense if combined with a strong and comprehensive programme of insulation and related measures. It is therefore difficult to be sure that you are comparing like with like - the different options may well imply very different levels of demand.

- Behavioural issues More generally, any vision of a low-carbon energy future is likely to be based on changes in consumer behaviour and in particular on more active consumer participation in 

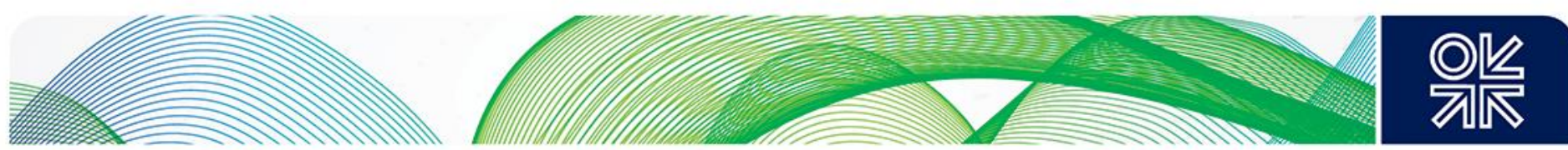

electricity markets via demand response, storage or self-generation. These behavioural responses are very difficult to predict at present; whether they will extend to heating as well as electricity is even more uncertain.

- Distributional and scale issues The various approaches to heat decarbonisation all entail a different balance between capital and fuel costs. The overall cost will depend to a large extent on the impact of energy efficiency measures on overall consumption (as noted above) and this may well affect the comparison between different routes - for instance, given the high capital costs of district heating, a scenario in which energy consumption was reduced significantly might make this option unviable. But there will also be distributional consequences - the impact on consumers will depend on their level of consumption, as illustrated in Chart 7.

\title{
Chart 7: Annual additional costs (£) versus consumption (MWh)
}

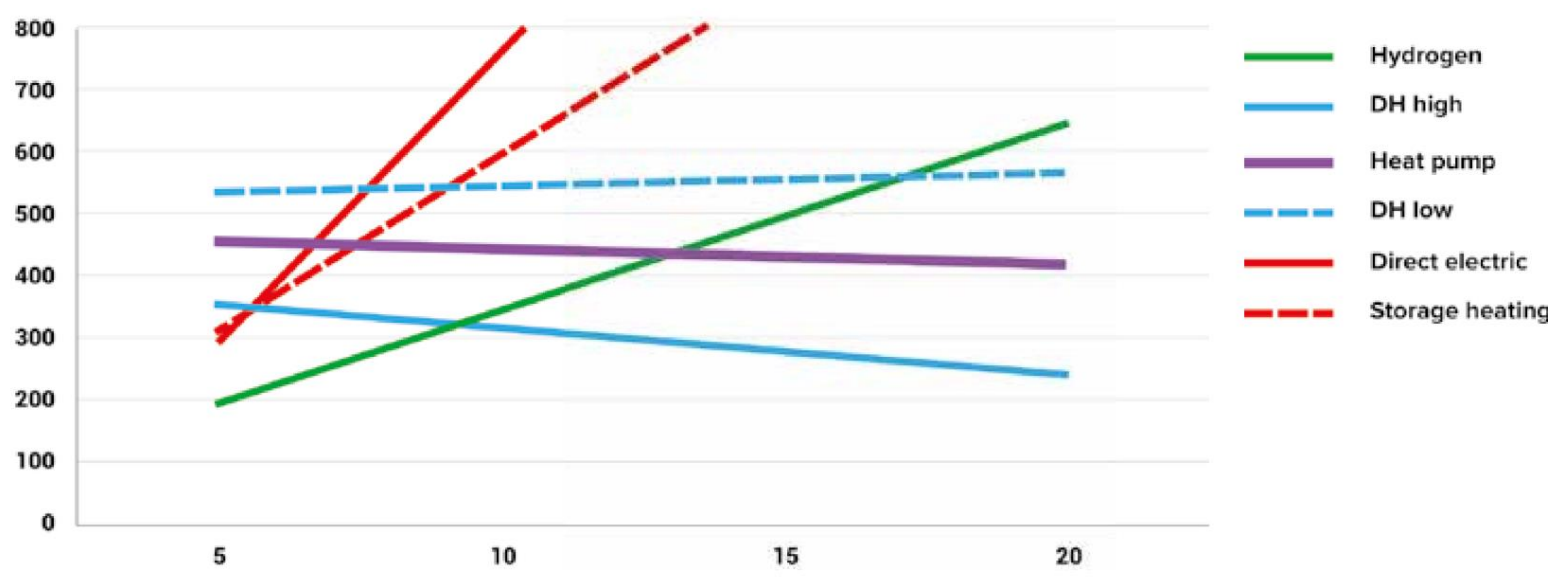

Source: NEA 2017

So it is not possible to give more than a preliminary assessment of the possible economics of a 'green gas' approach.

However, the studies referenced do at least suggest that the economics of this route are not necessarily an insuperable barrier, at least as compared with the alternatives. For instance, DECC 2013 comments that in view of the peakiness of heat demand:

'A model to identify the cheapest way to meet our low carbon ambitions will indicate that - all other things being equal - it is cheaper to meet this very high demand using the existing gas grid than making the additional extra investment in new power stations and electricity infrastructure that would be needed if it were to be primarily met through electric heating (including electric heat pumps).' (Introduction, paragraph 9).

Similarly, the Scottish Government in its draft Energy Strategy, argues that:

\begin{abstract}
'Hydrogen may have the potential to deliver the lowest cost and least disruptive solution for the decarbonisation of heat.....While more analysis will be required, there is some evidence to suggest that hydrogen can offer significant cost savings for customers compared to alternative low carbon heat sources such as electricity, or district heating.' (SES 2017, p 34-35)
\end{abstract}

Imperial 2016 does not give any simple cost comparison, but its cost analysis leads to the conclusion that all three main options need to be kept open (district heating, electrification and green gas) and that they might well be complementary, finding slightly different niches - district heating for new developments and neighbourhoods with strong 'anchor clients'; electrification for well insulated properties in less heavily populated areas; and green gas for mainstream urban and suburban areas. 

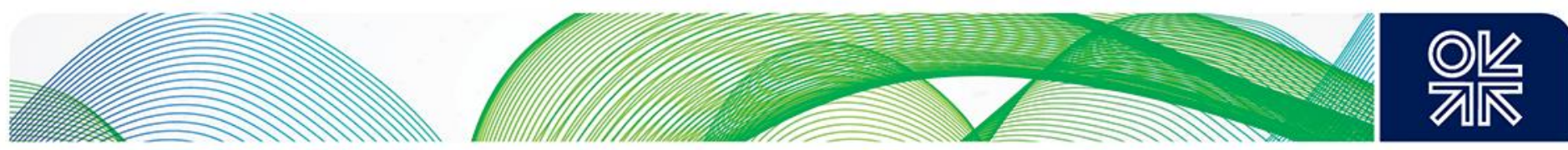

The H21 study suggests a sale price of hydrogen of around $8 \mathrm{p} / \mathrm{kWh}(\mathrm{p} 261)$. This is significantly more expensive than today's gas price (around $3 p / k W h$ ). Although the unit price is likely to be cheaper than electricity (c $14 \mathrm{p} / \mathrm{kWh}$ currently), the comparison is complicated. On the one hand, electricity offers high conversion efficiencies and may require a lower amount of infrastructure investment; on the other hand, electricity prices may increase because of the costs of accommodating intermittent renewable sources and the possible need to meet much higher peak demand. KPMG's analysis 'shows that removing gas from the energy mix and replacing it with electrical energy, while feasible, is higher cost and potentially more disruptive to customers.'

These are just examples - all the studies and their assumptions could of course be called into question and it is not the purpose of the present paper to revisit all these issues. The aim is merely to demonstrate that there is a prima facie case to suggest that the economics and practicability of the green gas has been sufficiently established to justify policy makers moving forward to more detailed scrutiny. This study is mainly concerned with looking at the practical steps which might be needed to make the option a real one - and it concludes that this is where the main barriers are likely to be found.

\section{Technological Issues}

The 'green gas' option faces major technical challenges, made more complicated by the fact that it is not a question of achieving an identifiable technical breakthrough but of establishing the viability of two technical routes, both of which face similar problems. In a sense, in both cases (hydrogen supply and CCS) the basic technologies are proven. In fact, over a decade ago, a widely cited paper on the 'stabilisation wedges' which would be needed to bring an end to the growth of carbon emissions treated both options as 'current technologies', and illustrated this by expressing the requirement in terms of an expansion of then existing capacity (Pacala and Socolow 2004):

'Option 6: Storage of carbon captured in power plants. Carbon capture and storage (CCS) technology prevents about $90 \%$ of the fossil carbon from reaching the atmosphere, so a wedge would be provided by the installation of CCS at $800 \mathrm{GW}$ of baseload coal plants by 2054 or $1600 \mathrm{GW}$ of baseload natural gas plants. The most likely approach has two steps: (i) precombustion capture of $\mathrm{CO}_{2}$, in which hydrogen and $\mathrm{CO}_{2}$ are produced and the hydrogen is then burned to produce electricity, followed by (ii) geologic storage, in which the waste $\mathrm{CO}_{2}$ is injected into subsurface geologic reservoirs. Hydrogen production from fossil fuels is already a very large business. Globally, hydrogen plants consume about $2 \%$ of primary energy and emit $0.1 \mathrm{GtC} /$ year of $\mathrm{CO}_{2}$. The capture part of a wedge of CCS electricity would thus require only a tenfold expansion of plants resembling today's large hydrogen plants over the next 50 years.....

Option 7: Storage of carbon captured in hydrogen plants. The hydrogen resulting from precombustion capture of $\mathrm{CO}_{2}$ can be sent off-site to displace the consumption of conventional fuels rather than being consumed onsite to produce electricity. The capture part of a wedge would require the installation of CCS, by 2054, at coal plants producing $250 \mathrm{MtH}_{2} /$ year, or at natural gas plants producing 500 $\mathrm{MtH}_{2} /$ year. The former is six times the current rate of hydrogen production.'

If these options were so apparent over a decade ago, why has progress on them been so slow, as compared with, say, renewables? The reason seems to be that both sets of technologies face similar problems, and that the problems are not narrowly technical in nature but socio-economic; if a simple laboratory breakthrough were all that is required it would in principle be relatively easy to test the viability of the technologies by undertaking the necessary research effort. But the difficulties lie in other areas:

- Future technological developments are always uncertain, of course, but there are no indications at present that major reductions in cost, such as those that have been seen in recent years in a number of renewable and storage technologies, are likely either in relation to carbon capture and storage or in relation to hydrogen production and distribution - precisely because the basic technologies are fairly well established. 

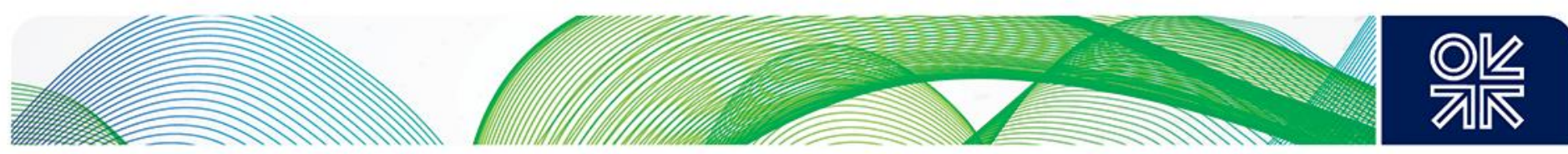

- The problem is therefore not so much that the individual technologies are unproven but that they need to be demonstrated in new combinations. For instance, although hydrogen production takes place on a wide scale at present, the distribution of hydrogen to residential consumers, and the capture of the $\mathrm{CO}_{2}$ generated in hydrogen production have not been tested at scale. Similarly, although $\mathrm{CO}_{2}$ capture takes place at many locations in the world today, large scale $\mathrm{CO}_{2}$ capture from fossil fuel combustion is less well understood (see below).

- These demonstrations are not easily scalable in the same way as, say, renewables. $\mathrm{CO}_{2}$ capture, or hydrogen distribution, for instance, encounter the same sort of economies of scale as in natural gas transportation, and use similar pipeline networks. A small-scale demonstration may give little idea of the implications or costs of a fully developed system, while a large-scale demonstration will inevitably be very expensive. By contrast, renewables have been introduced into electricity systems gradually, and at a steadily increasing scale, moving quickly up a practical learning curve.

- A number of separate activities would need to be coordinated in any demonstration (hydrogen generators; carbon capture, transportation and storage; consumer switching) but none of the actors would receive any direct benefit from being involved (carbon capture costs money and lowers efficiencies; consumers get no direct benefit from using hydrogen rather than natural gas; a commercial case needs to be established not just for carbon storage but also for the capture and transportation stages).

- Because of the above issues, to be convincing any demonstration would need to be relatively large scale and to coordinate the activities of many players, who would lack any direct commercial interest in the project - in other words the demonstration would require a considerable level of support from governments.

It is these complications which have slowed down progress on the technologies involved. Because both present rather similar problems it is worth looking at CCS' progress over the past two decades.

The technology has received high level policy and technical support. In 2003, the so-called Carbon Sequestration Leadership Forum was set up at Ministerial level to advance progress on carbon capture and storage; in 2005 the Intergovernmental Panel on Climate Change published a special report on CCS (IPCC 2005); and in 2009, the Global CCS Institute was established to champion the development, demonstration and deployment of CCS worldwide. Throughout this period, organisations such as the International Energy Agency have stressed how important CCS is in relation to carbon emissions reduction, arguing that, 'without CCS, the transformation of the power sector will be at least USD 3.5 trillion more expensive'. (IEA 2016 p 10) Yet, even its proponents acknowledge that progress has been relatively slow and that the pace needs to pick up if this goal is to be achieved - for example, while drawing attention to the many CCS projects under way, the Global CCS Institute also comments that, 'while it is very encouraging that more CCS facilities are becoming operational, the current level of CCS deployment does not go anywhere near what is required from CCS to meet the Paris 'well below' $2^{\circ} \mathrm{C}$ climate target. The uptake of CCS must be accelerated.'13

Over the same period, the UK government has been pressed to develop carbon capture and storage as a priority (PIU 2002; ETI 2015) and the Government has recognised the importance of the technology. Nonetheless, it did not succeed in getting any major projects under way. One of the key candidates was the so-called 'White Rose' project under which the Drax power station, in partnership with companies like Alstom and BOC would have developed a power station equipped with CCS and transported the $\mathrm{CO}_{2}$ captured via pipeline for storage in a depleted North Sea oil field. The project had the potential to act as an anchor for other CCS developments - it was based in an industrialised area of Yorkshire and the proposed $200 \mathrm{~km}$ pipeline was designed to enable potential future projects to

\footnotetext{
${ }^{13}$ https://www.globalccsinstitute.com/insights/authors/GlobalCCS\%20Institute/2017/05/08/major-strides-2017ccs?author=NjA3
} 

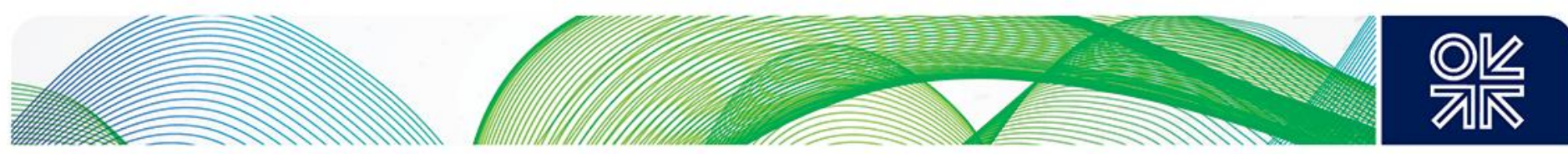

access the necessary infrastructure and facilitate CCS development. However, the project encountered various difficulties. Drax itself withdrew, partly because of changes in renewables support which had affected its cash flow, and the UK government announced in a statement to the stock market in November 2015 that it was scrapping its support for a £1bn CCS competition which would have helped finance the project. In April 2016, development consent was withheld, precisely because of the lack of funding. Another UK project, which had also hoped to benefit from the CCS competition, at Peterhead in Scotland was similarly stalled by the dropping of the competition fund.

The problem is not just a UK one. Norway has been a pioneer in the development of CCS, with the Sleipner project, but has similarly faced unacceptable risks and financial costs in relation to a major CCS project at the Mongstad oil refinery and power plant and has stopped development there. Similarly the 'Futuregen' project in the US, first announced by President George W Bush in 2003, has encountered a range of difficult challenges and, despite a series of self-reinventions, is currently suspended.

So while there has indeed been some progress over the past two decades it has not met expectations. Although the IEA notes that, "the number of large-scale CCS projects in operation has grown from three to 15 since Sleipner first started in 1996', it also laents that, 'for every large-scale CCS project that has been operating or has commenced construction since 2010, there are at least two projects that have been cancelled'.

The prospects for 'green gas' are inevitably affected by the future viability, or otherwise, of CCS. Without CCS, hydrogen generation would have to rely on other low carbon sources, like renewable electricity - which would call into question whether there was really any need for hydrogen as a carrier, given the ubiquity of electricity supply. Although the reverse is not necessarily the case (ie CCS could be viable, for electricity generation and industrial combustion), in practice, as discussed below, it could be that the prospect of a hydrogen-based energy system could prove a clinching argument for the development of CCS.

So, the futures of the two technologies are likely to be intertwined - adding further layers of complication. But either would require very substantial funding to develop further and - in the light of the difficulties which have been encountered with CCS - it is not clear that there is the political will, or sufficient prospective private benefit, to ensure that the funds needed will be available. Even a staged approach, which would examine particular aspects of the problem separately (and still leave open the question whether the coordination issues discussed above could be overcome) would be very expensive.

For instance, one current proposal is the so-called Cadent project ${ }^{14}$ which would create a Liverpool/Manchester hydrogen cluster. The idea is relatively limited - to supply a high hydrogen mix to selected industrial customers only, and to avoid the need for hydrogen storage by injecting any excess hydrogen beyond that needed for this purpose into the main natural gas distribution system up to agreed safety levels. In many ways, therefore, the most significant part of the project is the proposal to capture the carbon emissions from hydrogen production and store them in depleted hydrocarbon fields in Liverpool Bay. Even with these limited objectives, the costs involved are relatively high - capital expenditure requirements are estimated to be of the order of $£ 600$ million, with operating costs of nearly $£ 60$ million per annum. This is cheaper than the estimated cost of the $\mathrm{H} 21$ project (c£2billion of capex and £139 million per annum of operating expenditure) - but, of course, given the project's restricted scope, it would not demonstrate whether the wider use of 'green gas' for residential heating was viable. The project promoters would like to fund the project via their price control under the 'RIIO' mechanism ${ }^{15}$, which helps fund innovative projects (and financed the H21 study - though at a cost of only around

\footnotetext{
${ }^{14}$ http://cadentgas.com/About-us/Innovation/Projects/Liverpool-Manchester-Hydrogen-Cluster

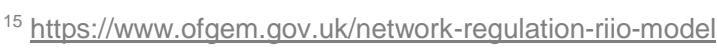



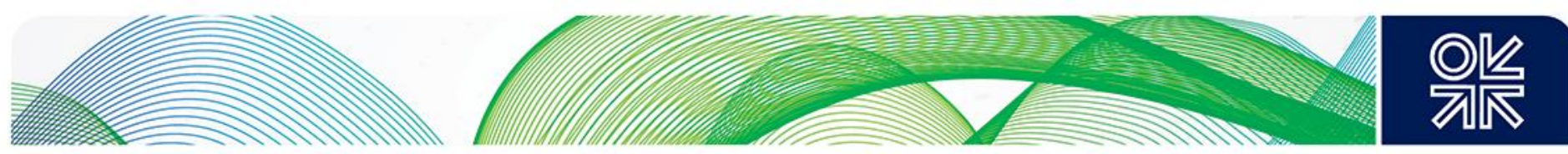

$£ 250,000$ ). In other words, the cost would fall on gas consumers, though it is not clear that they would receive any benefit - as noted above, it is this lack of clear benefit which makes such projects so difficult to commercialise.

Overall, therefore, the technical issues continue to be particularly intractable. Although a prima facie case has clearly been made for taking the 'green gas' option seriously, the complexity, the cost, the lack of any immediate benefit to the parties involved and the overall uncertainty mean it's not clear that it is preferable to other long-term options. Whoever tries to develop and demonstrate the technology will inevitably be taking (or asking others to take) considerable risks and it is not clear whether there is the appetite at present for taking those risks. In a sense, both CCS and hydrogen distribution are the 'wrong sort' of technology - they may have merit but it is difficult to find champions who are prepared to take the technologies forward, given the high costs and risks.

\section{Consumer issues and policy feasibility}

The discussion above suggests that, whatever the apparent technical feasibility of the 'green gas' option, the nature of the technology itself is likely to create obstacles to its early development. This section looks at the practical steps and policy instruments which might be needed to deliver a decarbonised heating system based on hydrogen. It draws in part on experience with electricity and the policies used there - as noted above, government intervention in electricity has increased (to the extent than most investment decisions in generation are now based on government schemes of one sort or another rather than on market signals). In the view of the author of this paper, this outcome was not inevitable. Over a decade ago ${ }^{16}$, he warned that governments needed to develop new policy instruments if they were going to incentivise the right sort of investment in electricity generation to meet environmental targets - if not, liberalisation would be undermined. In the event, it is indeed liberalisation that has been the primary casualty of decarbonisation in electricity. Is the same fate likely with gas?

It may first be worth considering why pure economic instruments were not used to promote the growth of renewables in electricity. Most economists would argue for a carbon tax or trading scheme as the most efficient mechanism to promote decarbonisation, yet the main policy choices for renewables in Europe have been Feed-In Tariffs and Renewables Obligations. The author has looked in more detail elsewhere at the reasons why carbon taxes were not the main policy of choice ${ }^{17}$; the reasons are summarised below.

Ultimately, the problem stems from a fundamental mismatch - relying on markets and market forces means accepting market outcomes, but environmental targets are nearly always expressed in terms of specific policy-favoured outcomes, in terms of the share of renewables, emissions reduction etc (rather than, say, in terms of addressing a market failure by incorporating relevant externalities).

This starting point entails fundamental strains, of which the following are examples:

- Credibility It is very difficult to make a carbon tax credible over a long enough term to act as a basis for investment. A new nuclear station, for instance, might take a decade to build then operate for a further four or five decades or more. Investors know from experience that it would be highly risky to rely on the stability and predictability of any tax over such a long period; with the European Emissions Trading Scheme the problems have been compounded by design faults. Prices have been low and volatile. Most studies conclude that the ETS has had little impact on investment. So governments committed to specific targets which entail high levels of (otherwise uneconomic) investment have in practice underpinned that investment by non-fiscal guarantees of one sort or another

\footnotetext{
${ }^{16}$ OIES 2006

${ }^{17}$ See, e.g. OIES 2016 d Chapter 8
} 

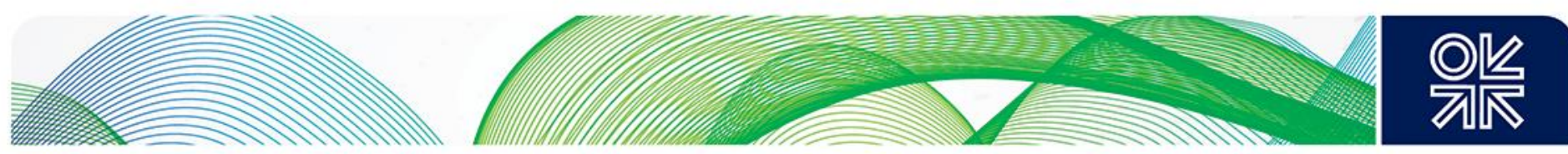

- Political issues Part of the problem is the political sensitivity of taxation and the fact that the ETS suffers from inherent political weaknesses. Since it requires agreement at European level, there is a tendency to go for the lowest common denominator. Many countries will simply not accept a scheme which will generate a tax high enough to have a significant effect on investment. Those countries wanting a higher tax have therefore resorted to unilateral action (as in the UK) but that then imposes new strains, in particular in relation to competitiveness; the UK quickly abandoned its initial objective of a steadily rising tax over time. All this feeds back into the credibility issue - it would be a foolish investor who would trust the political system to withstand all the pressures to adapt to changing circumstances.

- Consumer acceptability In principle, a carbon tax may be a low cost way of achieving a decarbonisation objective. In practice, however, taxes are highly visible and unpopular with consumers. It is true that at present those same consumers bear the cost of renewables support in other ways - and that it is at a level much higher than any conceivable carbon tax, at well over $€ 100$ per tonne of carbon ${ }^{18}$. Nonetheless, the cost is in general hidden within the electricity bill and, because of the confusing nature of the public debate about the cost of renewables, consumers often have little idea of the cost burden involved. Indeed, in many countries governments have sought to obscure the issue, for instance by not clearly identifying the extra system and network costs associated with the development of remote intermittent renewable sources ${ }^{19}$.

- Mitigating risk Renewables are in general very capital intensive; a major component in cost reduction is therefore reducing the cost of capital by reducing risk, for example by guaranteeing offtake volumes and prices. This consideration was important in motivating the shift from the Renewables Obligation to Feed-In Tariffs in the UK.

- Technology development The cost of renewables has fallen very substantially over time and there can be no doubt that the degree of government support given to the technologies has contributed significantly to this process. Looking ahead, there will still be a continuing need for new technology development, for instance in offshore wind and marine technologies. While support for research and development will be important, experience suggests that the main cost reductions come from the learning effects and economies of scale which are encouraged by significant deployment.

In other words, there have been strong reasons for governments to rely on specific instruments rather than an overall carbon tax or cap in its efforts to promote renewables in electricity.

Do similar arguments apply in relation to hydrogen for heating? In the view of this author, the arguments for a significant degree of central direction appear even stronger in this case. In addition to the factors mentioned above, they include the following:

- Competition As noted above, the relative lack of competition in the main applications of electricity facilitated the 'electricity first' approach. With gas, the position is more complex. While gas dominates the heating market, it does face potential competition from other sources; more significantly, hydrogen, if it were delivered as a separate option, would face competition from natural gas, unless the government arranged things to avoid such competition. For the consumer, there would be no advantage, and considerable costs, in a switch to hydrogen. These costs would involve adapting the consumer's own equipment plus the extra cost of the hydrogen itself arising from the efficiency losses involved in the steam reforming process; the cost of the reforming itself; the extra cost of CCS, and so on. It is difficult to estimate the full impact of these costs but as noted above, the calculations in $\mathrm{H} 212016$ suggest that delivered hydrogen could cost at least twice as much as today's natural gas supply. It is difficult to conceive of a politically viable tax which would

\footnotetext{
${ }^{18} \mathrm{lbid}$

${ }^{19}$ OIES 2013
} 

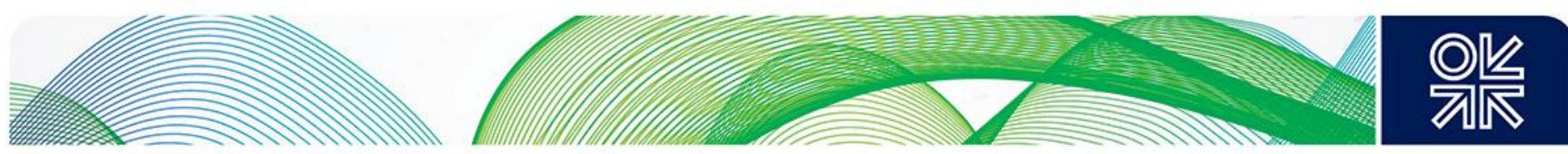

more than double the cost of gas to consumers, as would be required to bridge the price difference between natural gas and hydrogen; furthermore, any tax would still be open to the objections above in terms of credibility, risk and so on.

- Network issues A key difference between hydrogen and renewable electricity sources is that hydrogen would ultimately require a dedicated network. There is scope for mixing hydrogen into methane-carrying pipelines but that scope is relatively limited, maybe up to $20 \%$ - thereafter problems of embrittlement are encountered. Given the lower calorific value of hydrogen, the contribution to lowering emissions would be even lower in percentage terms (below 10\%). Renewables, by contrast, produce electricity which is indistinguishable at the consumer end, and within the transportation system, from other sources. This limited impact has facilitated both its penetration into the system and consumer acceptance. It has also enabled the cost to be 'socialised' (i.e. spread across all consumers) in a straightforward (and largely hidden) fashion. With hydrogen, such 'socialisation' of the cost is limited by the technical issues. If the long term emissions reduction target is to be met, a hydrogen-only system would need to be developed, rather than simply blending with natural gas in existing pipelines. This would require the development of single commodity networks, no doubt on an area by area basis. It would not then be possible for individual consumers to choose hydrogen or methane - the local network would have to carry one commodity only.

- Coordination issues The problem of coordination might seem highly technical but in fact could be fundamental to the development of a hydrogen system. The gas chain is complex - producers, transporters, aggregators, suppliers and consumers. For hydrogen to develop, each link would have to see a benefit. Furthermore, there would be additional links in the chain - methane reformers, carbon capture, transport and storage, consumer appliance conversion etc. With renewables in electricity the problem was largely upstream and confined within a single jurisdiction (indeed most renewables support schemes are by design aimed at plants within a particular country rather than at cross-border trade) ${ }^{20}$. It was therefore relatively easy to impose renewables obligations or to require suppliers to buy renewables on Feed-In Tariffs. With gas, by contrast, producers are often extra-territorial - indeed several borders may need to be crossed before getting to the final destination. Producers in, say, Russia or Algeria cannot be required to supply gas for hydrogen manufacture; given the novelty of the idea and the changes in business models required, they may not be keen to do so unless it seems more profitable for them and unless any risks can be mitigated. Similarly, consumers and other players may see no advantage for themselves in a switch to hydrogen and require incentives or regulation to persuade them to change. It appears to be primarily coordination issues of this sort which have so far slowed down the development of CCS - getting the incentives of all parties aligned, and the risks mitigated, involves a huge and highly complex effort. When many of the players are extra-territorial, the problem may be insuperable.

- Equity With electricity, as noted above, the costs of decarbonisation have been socialised across all consumers, mainly by government fiat. Since this has applied equally to all suppliers and consumers it has been broadly compatible with both equity and continuing competition between suppliers. It is difficult to see how this approach could be adopted with the development of hydrogen networks. As discussed above, it would not be practicable to convert the entire country overnight - instead, an area-by-area approach would need to be adopted, as set out in the H21 Report and as was the case with the conversion to North Sea gas in the 1970s. But the cost of hydrogen in the areas converted would be much higher than the cost of the gas they previously had available. It would not be equitable for consumers in one part of the country to pay a much higher price than those in another region simply because they happened to be first in line for the

\footnotetext{
${ }^{20}$ OIES 2016d
} 

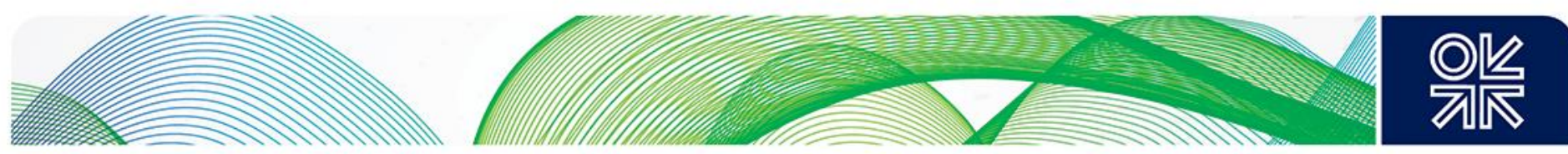

new network. Similarly, it would not make for a level playing field for competition if some suppliers happened to have a larger presence in that area than others - the higher prices would no doubt impact demand. Some way would have to be found of socialising the costs across the rest of the gas network, so that even those consumers who were not using hydrogen were bearing the cost equally. This would be much more visible politically, and much more problematic for competition, than the socialisation of renewables costs, which affects all consumers in a comparable fashion.

- Need for a long term strategy In the situation envisaged, there would be no market signals to optimise the system (eg to decide which areas to convert first; which new pipelines would need to be built; where to store the carbon generated; whether to convert the whole gas system or only metropolitan areas; whether industries should be allowed to continue with a separate natural gas supply etc). The long-term strategy would need to be decided centrally, communicated clearly to avoid investment uncertainty, and delivered in a systematic way. Regulation of pipelines and final markets would need to be consistent with the overall objective. This would imply central planning and coordination of a sort which could be incompatible with liberalised markets. While some would argue that the electricity industry has also suffered from the lack of a long-term strategy, and the inability of markets to give meaningful signals ${ }^{21}$, the problems there are less acute for the reasons given above; although liberalisation has suffered, it has not yet had to be abandoned explicitly.

All this means that it is very difficult to see how pure fiscal policy, or any 'stealth' policy entailing relatively limited effects on consumers, could deliver decarbonisation of heat through the routes identified to date, at least in the UK. Of course, as discussed in more detail in the parallel OIES paper on the decarbonisation of heat in Europe, it must be remembered that the situation in the UK is not exactly analogous to that in many other European countries, in particular because of the dominance of gas in heating and its very low cost as compared with electricity. For those consumers who already use electricity for heating, the use of heat pumps may be a viable alternative, if a reasonable package of incentives is offered. But those consumers are a small minority in the UK (unlike some other European countries). Furthermore, heat pumps require a significant change in consumer behaviour; they would not be viable without a quantum leap in household energy performance (which would in turn require a coherent strategic programme of improvement); and for them to be attractive to gas consumers, there would need to be improbably large incentives to bridge the gap between gas and electricity prices.

For those consumers using natural gas, there seems to be no conceivable fiscal incentive that could persuade them to switch to hydrogen, given the issues noted above. Intervention in the market - and a greater degree of intervention than that which has turned the electricity sector 'upside down' would be needed. Similarly, like any of the other options on the table - extension of heat networks or of biomass for instance - even more intervention would be required to secure take-up of hydrogen in significant quantities. That intervention would come in the form of regulation and central direction.

There are some major qualifications. First, time may alter the equation - higher gas prices and carbon taxes could change the relative attractiveness of gas heating, while cost reductions in renewable electricity, electricity storage, steam reforming or CCS might narrow the gap between gas and the lowcarbon options. But that requires a heroic set of optimistic assumptions, given the size of the gap to be bridged. The second qualification is that a first step might be to blend hydrogen into the existing gas system. That would not avoid many of the network, coordination, competition, equity and strategic issues listed above - it would be broadly similar to the promotion of renewables in electricity (though of course that has itself had huge impacts). It would also reduce emissions (but by well under $10 \%$ given the technical constraints and the low calorific value of hydrogen) and might be regarded as a preliminary step in establishing the viability of the steam reforming/CCS option - but it would not itself be anything

\footnotetext{
${ }^{21}$ E.g. OIES 2016a, OIES 2017
} 

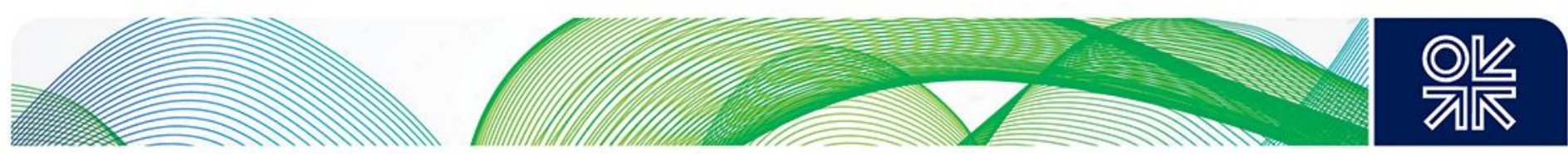

like sufficient to meet the long-term decarbonisation target and could therefore be regarded as an expensive diversion.

\section{Conclusions}

This study has looked at the ways in which the 'green gas' option might be taken forward in order to emerge as a fully realised policy option. It seems inevitable that for this to happen a high degree of government intervention would be required. For all the reasons discussed, the difficulties of relying primarily on market forces and fiscal signals in relation to the decarbonisation of heat via hydrogen are even greater than with electricity - and even there, of course, governments have generally resorted to interventionist policy instruments, rather than taxation, to achieve their objectives. Furthermore, with the 'green gas' option, the relatively invisible forms of support used for renewable electricity sources are not practical. It follows that the degree of government intervention required to deliver a hydrogen option would be even greater than with electricity - and might ultimately be incompatible with any sort of liberalised market. Indeed, in the view of the author, this might be an even more significant barrier to the development of this option than the economic and technical considerations. Governments are unlikely to resort to this degree of intervention unless convinced that there is really no alternative. That might mean they opted for a sub-optimal solution - the figures quoted above suggest that the hydrogen route might well be cheaper than the electricity route - but the history of decarbonisation policies does not give confidence that it is always the optimal route that is followed.

The problem is, in a sense, that 'green gas' involves the wrong sort of technology and the wrong sort of economics; it could only be delivered on the basis of a major strategic decision by the Government and a clear vision of the future low-carbon energy system. As far as the UK is concerned, this is difficult to envisage for a Government which the author has described as being in a state of 'ideological limbo' (Keay 2016) - needing to intervene increasingly in energy markets in order to achieve its decarbonisation objectives but unwilling to abandon its commitment to the use of market forces. It looks very difficult or impossible to square this circle in relation to 'green gas'. Even demonstrating the technical feasibility of the option would involve considerable complexity and expense and require significant market intervention, while offering no guarantee of success. Furthermore, it would still leave open the most difficult questions of all, those to do with political feasibility and consumer acceptance. To get through this thicket would require a very clear and determined government strategy; it is likely that it would only make sense if there was an overall vision of a hydrogen- based energy economy. In the present state of uncertainty such a clear vision seems unlikely. It would take a much higher degree of urgency (perhaps as a result of the failure of other options, an overwhelming case put forward by parties involved, including the industries themselves and an international consensus that this is the way forward) to create circumstances favourable for the development of such a vision; even if this favourable outcome should come to pass, there is a risk that it would then be too late, at least in terms of Europe's climate targets, given the long lead-times for establishing and then implementing the green gas option.

In any event, as the parallel OIES paper on decarbonisation of heat in Europe discusses in more detail, the UK is in many ways the most likely candidate for a 'green gas' initiative, so at least one of the factors mentioned above (international consensus on the option) is unlikely to develop, unless it has been preceded by extensive experience within the UK. It is therefore difficult, at least in present circumstances, to see a clear way forward for the technology. 

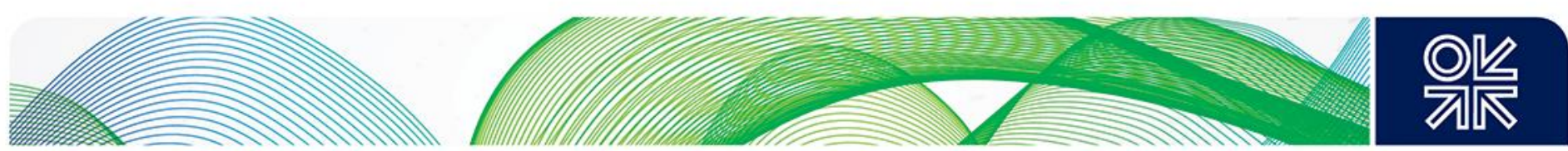

\section{References}

Cadent 2017 The Liverpool-Manchester Hydrogen Cluster: A low Cost deliverable project, Report by Progressive Energy Ltd August 2017

CCC 2008 Building a Low Carbon Economy- the UK's Contribution to Tackling Climate Change Committee on Climate Change, London, December 2008

CCC 2016 Next steps for UK heat policy Committee on Climate Change, October 2016

DECC 2013 The Future of Heating: Meeting the Challenge, Department of Energy and Climate Change, March 2013

Dodds and Hawkes 2014 Dodds, P.E. and Hawkes A. (Eds) 2014. The role of hydrogen and fuel cells in providing affordable, secure low-carbon heat. H2FC SUPERGEN, London, UK.

EC 2011 Roadmap for moving to a competitive low-carbon economy in 2050, European Commission 2011

Element 20122050 options for decarbonising heat in buildings. Element Energy and AEA Group. Report to Committee on Climate Change, London 2012

ERP 2011 The future role for energy storage in the UK Energy Research Partnership, June 2011

ERP 2016 Potential role of Hydrogen in the UK Energy System Energy Research Partnership, October 2016

ETC 2017 Better Energy, Greater Prosperity, Energy Transitions Commission, April 2017

ETI 2015a Carbon capture and storage: Building the UK carbon capture and storage sector by 2030 Scenarios and actions, Energy Technologies Institute, Loughborough 2015

ETI 2015b CCS Sector Development Scenarios in the UK Report for the Energy Technologies Institute by Element Energy April 2015

Eyre and Baruah 2015 Eyre, N. and Baruah P. Uncertainties in future energy demand in UK residential heating Energy Policy 87 (2015) 641-653

Green Gas 2016 The Green Gas Book Parliamentary Labour Party Energy and Climate Change Committee, London Summer 2016

H21 2016 The H21 Leeds City Gate Project Northern Gas Networks 2016

HMG 2017 The Clean Growth Strategy, HM Government October 2017

IEA 201620 Years of Carbon Capture and Storage: Accelerating Future Deployment IEA Paris 2016

IPCC 2005 Carbon Dioxide Capture and Storage, Special Report by the Intergovernmental Panel on Climate Change, December 2005

Keay 2016 Keay M., UK Energy Policy: stuck in ideological limbo? Energy Policy, vol 94, p 247-252

KPMG 20162050 Energy Scenarios: the UK gas networks role in a 2050 whole energy system, KPMG July 2016

Maclean et al 2016 MacLean,K., Sanson, R., Watson, T. and Gross, R. Managing Heat System Decarbonisation Imperial College, London April 2016

Manifesto 2017 For the many, not the few, The Labour Party Manifesto 2017

NEA 2017 Heat Decarbonisation: Potential Impacts on Social Equity and Fuel Poverty National Energy Action September 2017 

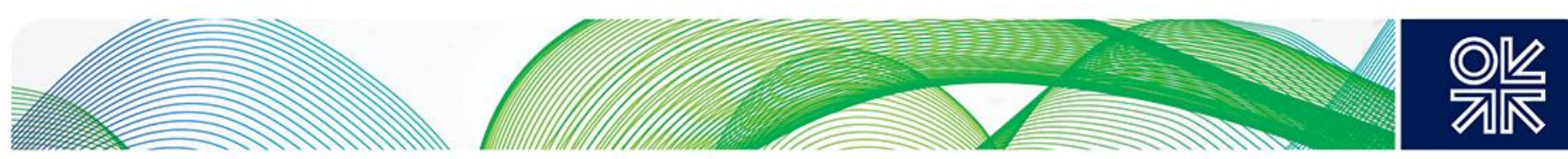

NG2017 National Grid, Future Energy Scenarios National Grid, UK, July 2017

NG2018 National Grid, The Future of Gas National Grid, UK, March 2018

OEF 2016a Oxford Energy Forum Issue 104, March 2016

OEF 2016b Oxford Energy Forum Issue 105, June 2016

OIES 2013a Keay M., Renewable Energy Targets: the importance of system and resource costs, Oxford Institute for Energy Studies, February 2013

OIES 2013 b Keay M., The EU "Target Model" for electricity markets: fit for purpose? Oxford Institute for Energy Studies, May 2013

OIES 2015 Robinson D., The Scissors Effect - How structural trends and government intervention are damaging the major European electricity companies and affecting consumers Oxford Institute for Energy Studies, August 2015

OIES 2016a Keay M., Electricity markets are broken - can they be fixed? Oxford Institute for Energy Studies, January 2016

OIES 2016b Buchan D. and Keay M. 2016 Europe's Long Energy Journey: towards an energy union? Oxford University Press 2016

OIES 2017 Keay M., and Robinson D. Managing Electricity Decarbonisation: learning from experience - the cases of the UK and Spain Oxford Institute for Energy Studies, April 2017

Oxburgh 2016: Lowest cost decarbonisation for the UK:The critical role of CCS.

Report to the Secretary of State for Business, Energy and Industrial Strategy from the Parliamentary Advisory Group on Carbon Capture and Storage

Pacala and Socolow 2004 Pacala, S. and Socolow, R. Stabilization Wedges: Solving the Climate Problem for the Next 50 Years with Current Technologies Science, 13 August 2004, Vol. 305, No. 5686, pp 968-972

Policy Connect 2017 Next steps for the Gas Grid: Future Gas Series Part 1 Policy Connect/Carbon Connect 2017

Policy Exchange 2016 Too hot to handle: how to decarbonise domestic heating, Policy Exchange, London 2016

PIU 2002 The Energy Review, Performance and Innovation Unit, February 2002

RIIA 2017 Woody Biomass for Power and Heat: Impacts on the Global Climate, Royal Institute for International Affairs, February 2017.

SES 2017 Scottish Energy Strategy: The future of energy in Scotland Scottish Government, January 2017

SGI 2016 Can Technology unlock 'unburnable carbon'? White Paper by Imperial College/Sustainable Gas Institute May 2016

Sioshansi 2014 Distributed Generation and Its Implications for the Utility Industry, Sioshansi F. P. (ed), Elsevier Academic Press, 2014

UKERC 2018 A Transformation to Sustainable Heating in the UK: risks and opportunities, UK Energy Research Council, February 2018 